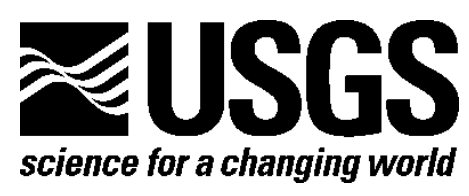

\title{
Modeling Managed Flows in the Sacramento/San Joaquin Watershed, California, Under Scenarios of Future Change for CASCaDE2
}

By Noah Knowles and Collin Cronkite-Ratcliff

Open-File Report 2018-1101

U.S. Department of the Interior

U.S. Geological Survey 


\section{U.S. Department of the Interior \\ RYAN K. ZINKE, Secretary}

U.S. Geological Survey
James F. Reilly II, Director

U.S. Geological Survey, Reston, Virginia: 2018

For more information on the USGS—-the Federal source for science about the Earth, its natural and living resources, natural hazards, and the environment-visit https://www.usgs.gov/ or call 1-888-ASK-USGS (1-888-275-8747).

For an overview of USGS information products, including maps, imagery, and publications, visit https://store.usgs.gov/.

Any use of trade, firm, or product names is for descriptive purposes only and does not imply endorsement by the U.S. Government.

Although this information product, for the most part, is in the public domain, it also may contain copyrighted materials as noted in the text. Permission to reproduce copyrighted items must be secured from the copyright owner.

Suggested citation:

Knowles, Noah, and Cronkite-Ratcliff, Collin, 2018, Modeling managed flows in the Sacramento/San Joaquin watershed, California, under scenarios of future change for CASCaDE2: U.S. Geological Survey Open-File Report 2018-1101, 38 p., https://doi.org/10.3133/ofr20181101. 


\section{Acknowledgments}

We thank the California Department of Water Resources for guidance on questions related to the CalSim 2 model. We also thank Ann Willis, University of California, Davis, for her guidance and the U.S. Army Corps of Engineers for providing reservoir operating manuals. We are grateful for support from the Delta Stewardship Council's Science Program.

We thank Michael Dettinger, U.S. Geological Survey (USGS), for his helpful review of this report. We are grateful for support from the following USGS programs: Priority Ecosystems Science, which is part of the USGS Ecosystems Mission Area, and the Water Availability and Use Science Program and the National Water Quality Program, which are part of the Water Mission Area. Finally, we are grateful for the support and collaboration from our colleagues on the CASCaDE team. Data and associated code generated during this study are available as a USGS data release (Knowles and others, 2018). 


\section{Contents}

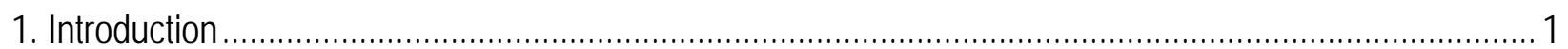

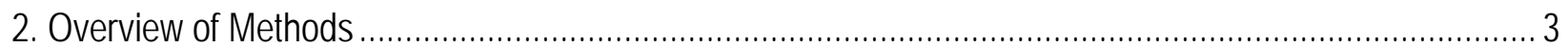

2.1. Climate Change Scenarios and Downscaling ..................................................................... 3

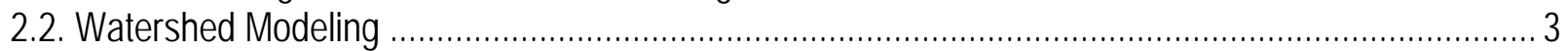

3. RVIC Unimpaired Streamflow Simulations and Postprocessing ................................................... 6

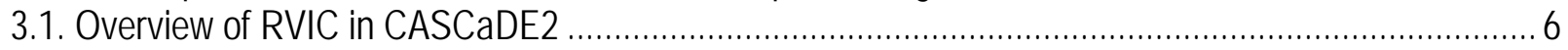

3.2. Bias-Correcting RVIC Unimpaired Flows for Use in Producing C2-CalSim Water-Year Indexes ........ 6

3.3. Transforming Unimpaired RVIC Flows to Managed Flows for Use as C2-CalSim Flow Inputs ............ 8

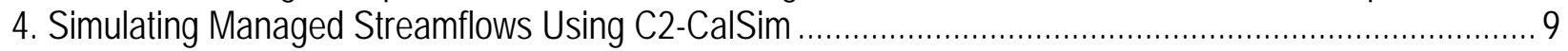

4.1. CalSim 2 Description ................................................................................................ 9

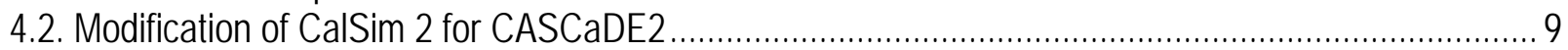

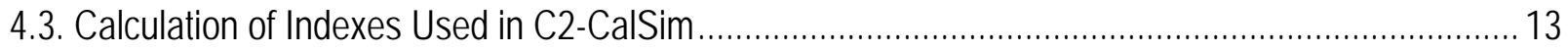

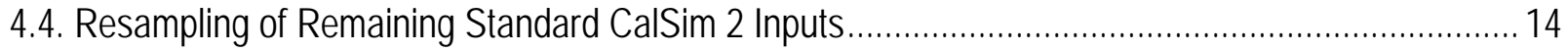

4.5. Sequential Execution of C2-CalSim Studies........................................................................... 16

4.6. Automating C2-CalSim Runs..................................................................................... 17

4.7. Application of C2-CalSim in CASCaDE2: Limitations and Future Work ........................................ 17

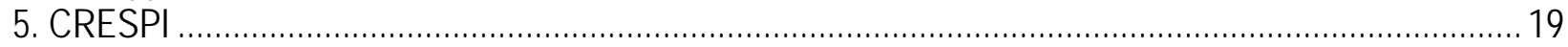

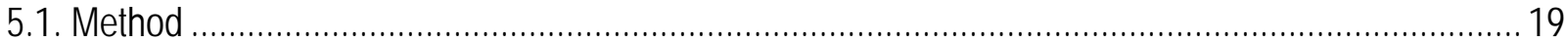

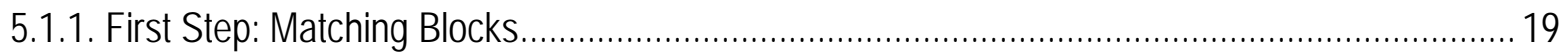

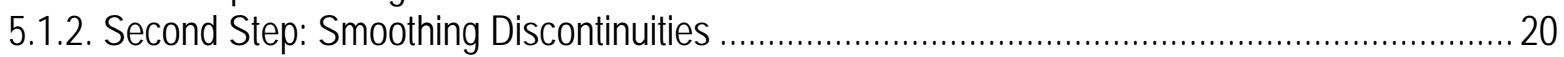

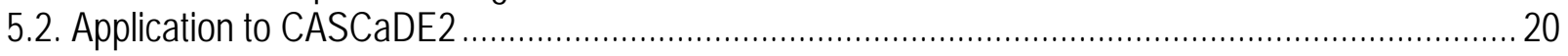

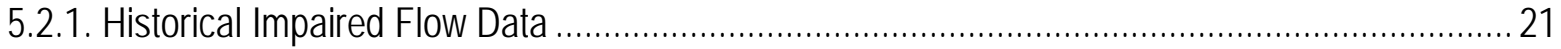

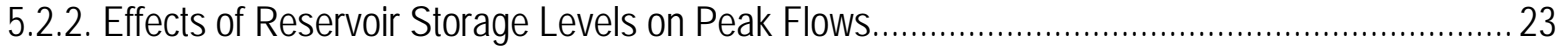

5.2.2.1. Modeling the Flood Control Reservation.................................................................. 23

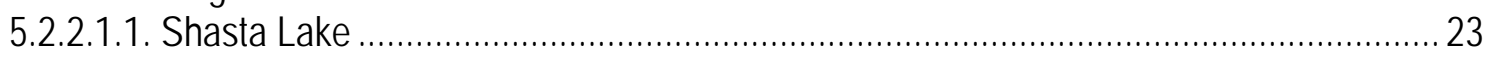

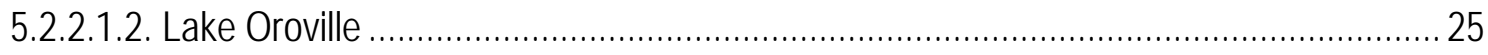

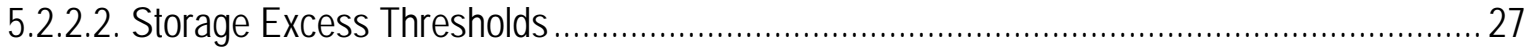

5.2.3. Modeling Separation of Flow by Fremont Weir ............................................................ 29

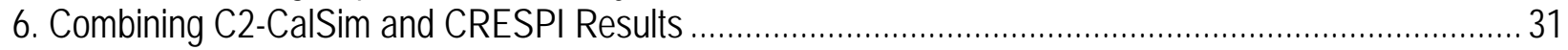

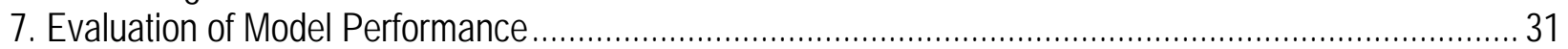

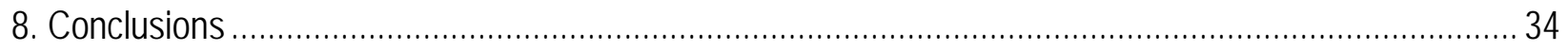

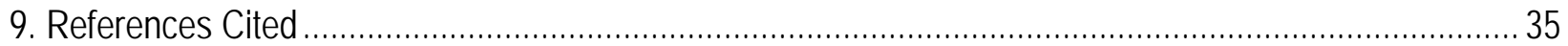

\section{Figures}

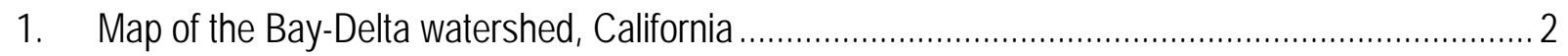

2. Schematic showing the role of watershed modeling in the Computational Assessments of Scenarios of Change for the Delta Ecosystem project phase 2 (CASCaDE2) for the Sacramento-San Joaquin Delta, California.....

3. Flowchart showing the modeling of managed daily flows at points throughout the Sacramento River Basin, California

4. Graphs showing observation-based, simulated Variable Infiltration Capacity hydrologic model plus Variable Infiltration Capacity routing model $(\mathrm{VIC}+\mathrm{RVIC})$, and bias-corrected unimpaired 
Sacramento River Basin, California, total monthly flows, and simulated and bias-corrected

flows versus observation-based flows.

5. Map showing major creeks and rivers in the San Francisco Bay and Sacramento-San Joaquin Delta (Bay-Delta) watershed, California, corresponding to CASCaDE2 modified CalSim (California Department of Water Resources' operations model) (C2-CalSim) inflow boundaries

6. Graph showing rule curve for Shasta Lake, California, calculated over the range of ground wetness parameters.

7. Rule curve for Lake Oroville, California, calculated over the range of ground wetness parameters.

8. Graphs showing the 30-day moving maximum storage excess in Shasta Lake and Lake Oroville reservoirs, California, versus the 30-day moving maximum daily impaired flow rates ................. 28

9. Graph showing implementation of culling for Shasta Lake, California ........................................ 29

10. Graph showing mean daily flow over Fremont Weir versus flow in Yolo Bypass near Woodland, California, 1984-2010.....

11. Evaluation of performance of combined C2-CalSim/CRESPI method for Sacramento River Basin, California, outflows for the historical period, water years 1980-2013

\section{Tables}

1. Locations in San Francisco Bay and Sacramento-San Joaquin Delta (Bay-Delta) watershed, California, of CASCaDE2 modified CalSim (California Department of Water Resources' operations model) (C2-CalSim) inflow boundary conditions that are derived from global climate model driven Variable Infiltration Capacity routing model (RVIC) daily flow estimates.

2. Streamflow station records from the San Francisco Bay and Sacramento-San Joaquin Delta (Bay-Delta) watershed, California, used as historical data in the Computational Assessments of Scenarios of Change for the Delta Ecosystem phase 2 (CASCaDE2) resampling algorithm (CRESPI) method .

3. Average annual precipitation measured at eight rain gauges in the vicinity of the Feather River Basin, California

4. Intramonthly performance metrics at inflow boundary locations for the San Francisco Bay and Sacramento-San Joaquin Delta (Bay-Delta) estuarine hydrodynamical model, Deltares Flow Flexible Mesh hydrodynamical model (D-Flow FM)

5. Intra-WY performance metrics at inflow boundary locations for the San Francisco Bay and Sacramento-San Joaquin Delta (Bay-Delta) estuarine hydrodynamical model, Deltares Flow Flexible Mesh hydrodynamical model (D-Flow FM) 


\section{Conversion Factors}

U.S. customary units to International System of Units

\begin{tabular}{|c|c|c|}
\hline Multiply & By & To obtain \\
\hline \multicolumn{3}{|c|}{ Length } \\
\hline inch (in.) & 2.54 & centimeter $(\mathrm{cm})$ \\
\hline foot (ft) & 0.3048 & meter $(\mathrm{m})$ \\
\hline \multicolumn{3}{|c|}{ Flow Volume } \\
\hline acre-foot & 1,233 & cubic meters \\
\hline \multicolumn{3}{|c|}{ Flow rate } \\
\hline cubic foot per second $\left(\mathrm{ft}^{3} / \mathrm{s}\right)$ & 0.02832 & cubic meter per second $\left(\mathrm{m}^{3} / \mathrm{s}\right)$ \\
\hline
\end{tabular}

Temperature in degrees Celsius $\left({ }^{\circ} \mathrm{C}\right)$ may be converted to degrees Fahrenheit $\left({ }^{\circ} \mathrm{F}\right)$ as follows: ${ }^{\circ} \mathrm{F}=\left(1.8 \times{ }^{\circ} \mathrm{C}\right)+32$.

Temperature in degrees Fahrenheit $\left({ }^{\circ} \mathrm{F}\right)$ may be converted to degrees Celsius $\left({ }^{\circ} \mathrm{C}\right)$ as follows: ${ }^{\circ} \mathrm{C}=\left({ }^{\circ} \mathrm{F}-32\right) / 1.8$.

\section{Abbreviations}

$\mathrm{AF}$

ANN

BDCP

C2-CalSim

CASCaDE

CASCaDE2

CDF

CDWR

CMIP5

CRESPI

D-Flow FM

EC

GCM

LOCA

LOD

NAA

PA

QMBC

RCP

RMS

RSR

RVIC

SLR

USGS

VIC

WSI-DI

WY adjustment factor

artificial neural network

Bay-Delta Conservation Plan

CASCaDE2 modified CalSim (CalSim is CDWR's operations model)

Computational Assessments of Scenarios of Change for the Delta Ecosystem

Computational Assessments of Scenarios of Change for the Delta Ecosystem phase 2

cumulative distribution function

California Department of Water Resources

Coupled Model Intercomparison Project Phase 5

CASCaDE2 resampling algorithm

Deltares Flow Flexible Mesh hydrodynamical model

existing conditions

global climate model

localized constructed analogs (downscaling method)

level of development

no action alternative

preferred alternative

quantile-mapping bias correction

representative concentration pathway

root-mean-square

ratio of the root mean square error to the standard deviation of observations

VIC routing model

sea-level rise

U.S. Geological Survey

Variable Infiltration Capacity hydrologic model

Water Supply Index-Delivery Index

water year (October 1-September 30) 


\title{
Modeling Managed Flows in the Sacramento/San Joaquin Watershed, California, Under Scenarios of Future Change for CASCaDE2
}

\author{
By Noah Knowles and Collin Cronkite-Ratcliff
}

\begin{abstract}
Projections of managed flows from the Sacramento River/San Joaquin River watershed, California, into the San Francisco Bay and Sacramento-San Joaquin Delta under scenarios of future climate change are needed for evaluations of potential impacts on water supply and estuarine ecosystems. A new, multiple-model approach for achieving this is described. First, downscaled global climate model outputs are used to drive an existing Variable Infiltration Capacity/Variable Infiltration Capacity Routing (VIC/RVIC) model of Sacramento/San Joaquin hydrology, resulting in projections of daily, unimpaired flows (flows unaffected by management infrastructure such as reservoirs, diversions, exports, and so on) throughout the watershed. A management model, Computational Assessments of Scenarios of Change for the Delta Ecosystem phase 2 (CASCaDE2) modified CalSim (C2-CalSim), uses these projections as inputs and produces monthly estimates of reservoir and other infrastructure operations and resulting downstream managed flows. A historical resampling algorithm, CASCaDE2 resampling algorithm (CRESPI), also uses the projected daily unimpaired flows, along with historical managed flows, to estimate the daily variability in managed flows (flows that have been altered by management infrastructure and actions) throughout the watershed. The monthly and daily managed-flow estimates are combined in a way that preserves the multi-decadal variability and century-scale trends produced by the C2-CalSim model and the day-to-day variability produced by the CRESPI algorithm. The performance of the new modeling approach is evaluated at major inflows to the Bay-Delta estuary using multiple metrics and found to be satisfactory for the purposes of future scenario evaluation.
\end{abstract}

\section{Introduction}

Together, California's San Francisco Bay and the adjacent upstream delta of the Sacramento and San Joaquin Rivers (the "Delta") are the largest estuary on the west coast of the conterminous United States. Although local watersheds contribute inflow into San Francisco Bay, the vast majority of inflows to Bay-Delta estuary arrive through the Delta from the combined watershed of the Sacramento and San Joaquin Rivers (fig. 1). This watershed's area is about 30 percent of California's area and it receives an average of 77 million acre-feet of precipitation annually. The Delta is home to vital ecosystems, providing habitat for many endangered species and serving as an important stop for migrating birds on the Pacific Flyway. The Delta provides drinking water to two-thirds of Californians and is a major source of water for California agriculture (National Research Council, 2012). The health of the estuary's ecosystem has long been in decline (for example, Healey and others, 2008). Continued subsidence of Delta islands, in conjunction with sea-level rise and the likelihood of major earthquakes, threaten 
hundreds of miles of fragile levees (Mount and Twiss, 2005). As a result, the Delta's ecosystem and the role of its waterways as a central conduit for transporting freshwater from north to south are vulnerable. In response to these problems, California passed the Sacramento-San Joaquin Delta Reform Act of 2009 (see http://deltacouncil.ca.gov/enabling-legislation) with the coequal goals of achieving water supply reliability and restoring the Delta's ecosystem. However, critical gaps in our understanding of how the Delta may respond to major changes that are likely over the next several decades complicate decisions concerning how to achieve these goals.

The Computational Assessments of Scenarios of Change for the Delta Ecosystem project, now in its second phase (CASCaDE2), is an interdisciplinary modeling research effort aimed at projecting responses of the San Francisco Bay-Delta estuary and the Sacramento/San Joaquin watershed under scenarios of future change. The changes being investigated in CASCaDE2 include climate change through 2100 and major infrastructure changes, including tunnels under the Delta to provide an alternative to through-Delta conveyance of freshwater from north to south. Ultimately, CASCaDE2 is aimed at providing an improved understanding and a new capability to model the effects of future changes on the Delta ecosystem. A critical step toward that goal is the development of projections of managed flows in the Sacramento/San Joaquin watershed under the future scenarios. The methods developed and applied to that end in CASCaDE2 are the subject of this report.

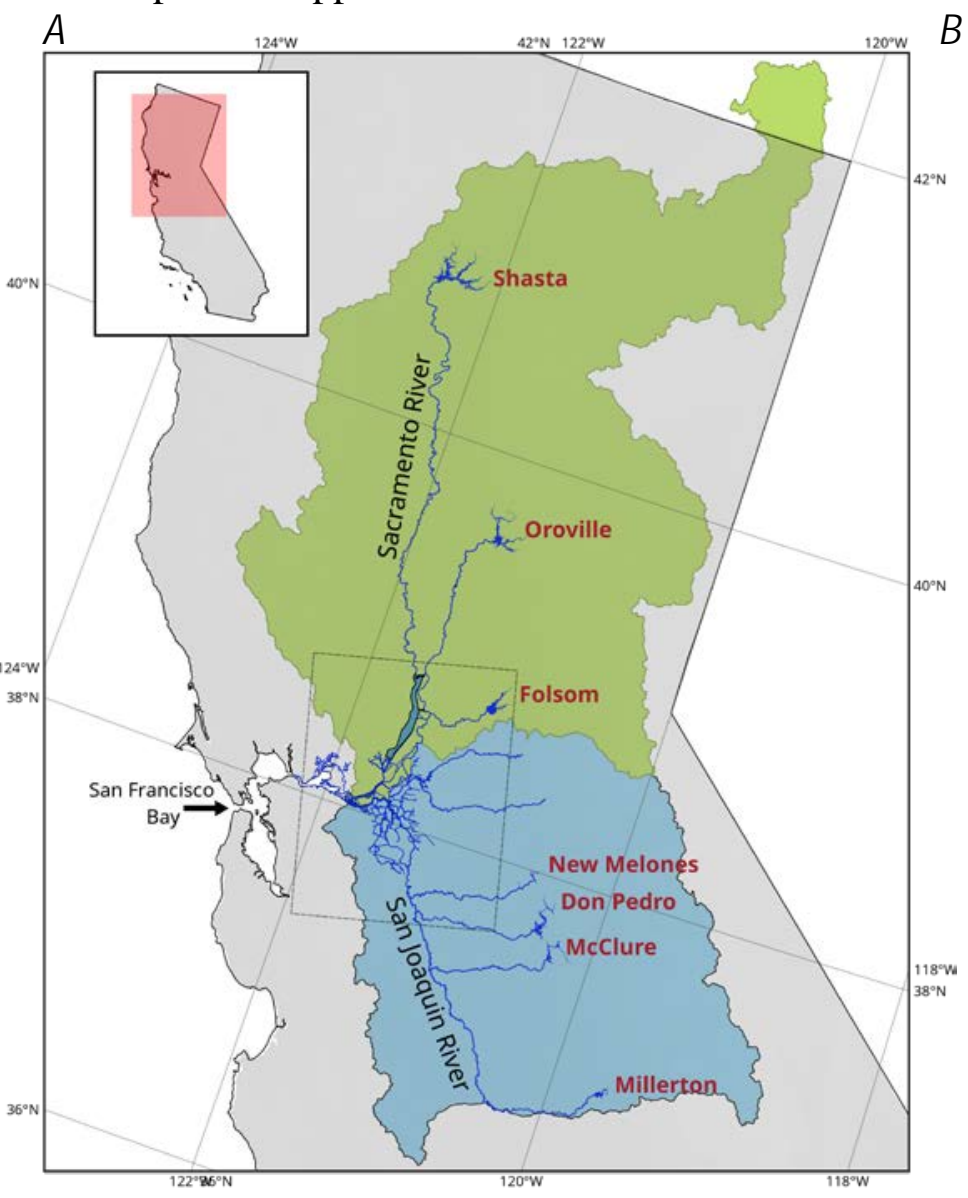

$B$

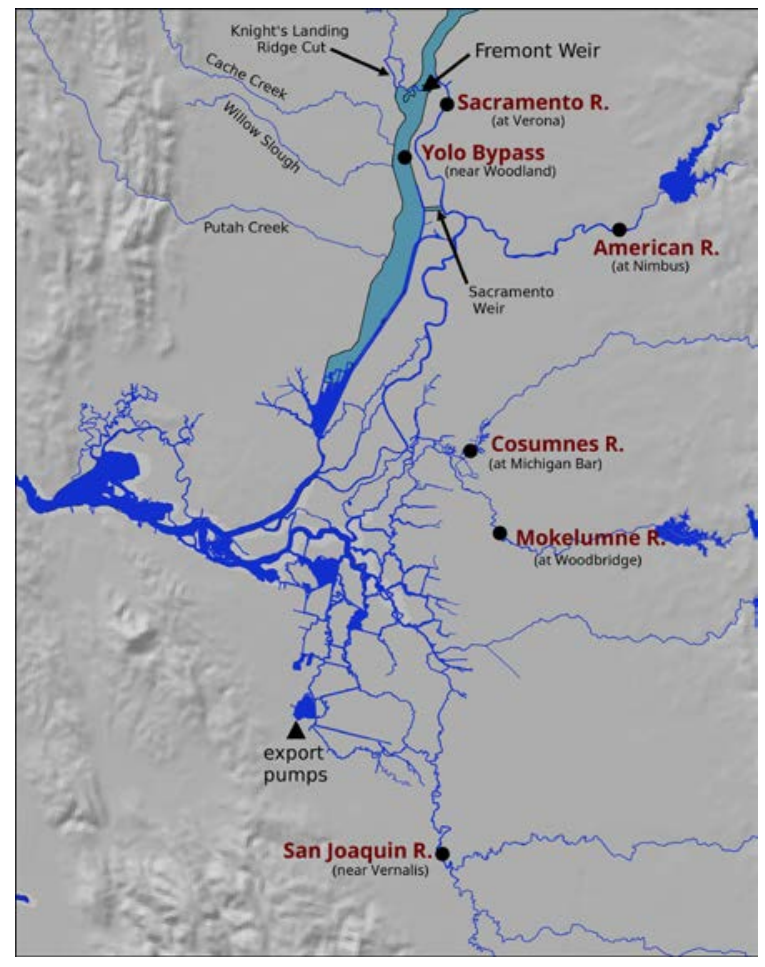

Figure 1. A, Map of the Bay-Delta watershed, California, with Sacramento and San Joaquin basins shaded green and blue, respectively, and major reservoirs labeled in red. The dashed rectangle in $A$ indicates the Delta region, which is mapped in $B$ with locations of major Delta freshwater inflows labeled in red. Base map sources: U.S. Geological Survey and Esri. 


\section{Overview of Methods}

\subsection{Climate Change Scenarios and Downscaling}

The CASCaDE2 project makes use of 20 climate change scenarios. These correspond to two runs each of ten global climate models (GCMs: ACCESS1-0, CanESM2, CCSM4, CESM1-BGC, CMCC-CMS, CNRM-CM5, GFDL-CM3, HadGEM2-CC, HadGEM2-ES, and MIROC5. Each model was run with two scenarios of future greenhouse gas concentrations, or representative concentration pathways (RCPs). The two RCPs evaluated correspond to radiative forcing values in 2100 of 4.5 watts per square meter $\left(\mathrm{W} / \mathrm{m}^{2}\right)$ and $8.5 \mathrm{~W} / \mathrm{m}^{2}$. These scenarios were selected from the full Coupled Model Intercomparison Project Phase 5 (CMIP5) ensemble as suitable for California water-resources assessments (California Department of Water Resources, Climate Change Technical Advisory Group, 2015). Outputs from each GCM/RCP scenario were bias-corrected using a recently developed method (Pierce and others, 2015) and downscaled using the Localized Constructed Analogs (LOCA) method (Pierce and others, 2014), resulting in sets of daily projections of precipitation and near-surface air temperature on a $1 / 16^{\circ}$ grid containing the Sacramento/San Joaquin watershed for the period 1950-2100 (in most cases; some GCM runs end in 2099). Note that the values over the historical period in these GCM outputs are simulated climate responses to historical greenhouse gas fluctuations and are constrained by no other historical forcings. As such, their interannual and decadal variability differ from recorded historical behavior, despite coverage of the same nominal period. In addition to these purely GCM-based climate change scenarios, an observation-based dataset (Livneh and others, 2015) on the same $1 / 16^{\circ}$ grid was used to provide a historical baseline for comparison with future scenarios for the period including water years ${ }^{1}$ (WYs) 1950-2013. This is also the dataset that Pierce and others (2014) used as the historical reference in their GCM bias correction and downscaling.

\subsection{Watershed Modeling}

The primary goal of the work described in this report was to translate future scenarios of downscaled daily precipitation and temperature fields into estimates of daily managed downstream flows at points throughout the watershed. Managed flows reflect the influences of reservoirs, diversions, groundwater pumping, and so forth, under a set of management goals and criteria. Additionally, a set of managed flow "hindcasts" was produced for the historical period using the same modeling tools and the observation-based dataset from Livneh and others (2015), providing a historical baseline for comparison with the future scenarios. In the CASCaDE2 project, the resulting managed flow projections have served as inputs for a new Sacramento watershed sediment model (Stern and others, 2016), and managed flows from a subset of the future scenarios are being used to drive a new hydrodynamical model of the Bay-Delta estuary called the Deltares Flow Flexible Mesh hydrodynamical model (D-Flow FM) (Martyr-Koller and others, 2017) (fig. 2).

\footnotetext{
${ }^{1} \mathrm{~A}$ water year is defined as the 12-month period from October 1 of any given year through September 30 of the following year. The water year is designated by the calendar year in which it ends and which includes 9 of the 12 months.
} 


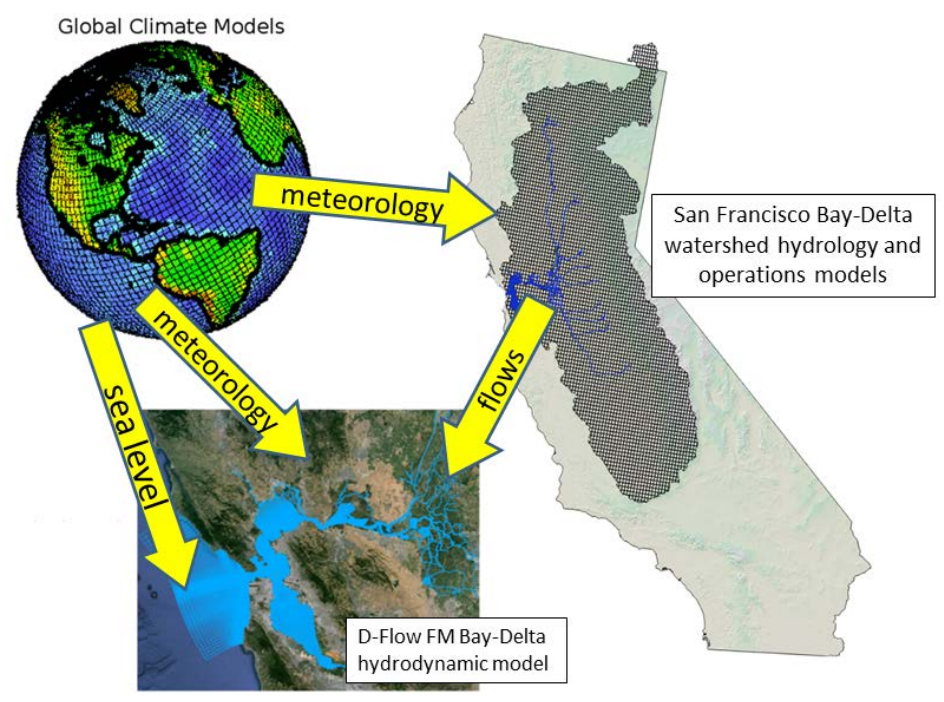

Figure 2. Schematic showing the role of watershed modeling in the Computational Assessments of Scenarios of Change for the Delta Ecosystem project phase 2 (CASCaDE2) for the Sacramento-San Joaquin Delta, California. Downscaled global climate model (GCM) outputs drive watershed and estuary models. Watershed hydrology and operations models translate global climate model outputs into managed estuarine inflows.

To produce the managed flow estimates at relevant points throughout the watershed, a combination of models was used (fig. 3). First, in simulations performed at Scripps Institution of Oceanography by David Pierce (University of California, San Diego, written commun., 2017), the Variable Infiltration Capacity (VIC) hydrological model (Liang and others, 1994; Livneh and others, 2013) was driven by the downscaled meteorological data. The resulting simulated fields of gridded unimpaired ${ }^{2}$ surface runoff and subsurface flow were routed to produce unimpaired streamflow estimates using the VIC routing model RVIC (Lohmann and others, 1996; Hamman and others, 2016) configured for the CASCaDE2 spatial domain for this study.

${ }^{2}$ In this document, "impaired" or "managed" flows are flows that have been altered by management infrastructure, including reservoirs, diversions, exports, and so on. "Unimpaired" flows are estimates of flows that would have occurred without these impairments. 


\section{GCMs $\Rightarrow$ LOCA $\Rightarrow$ VIC $\Rightarrow$ RVIC}

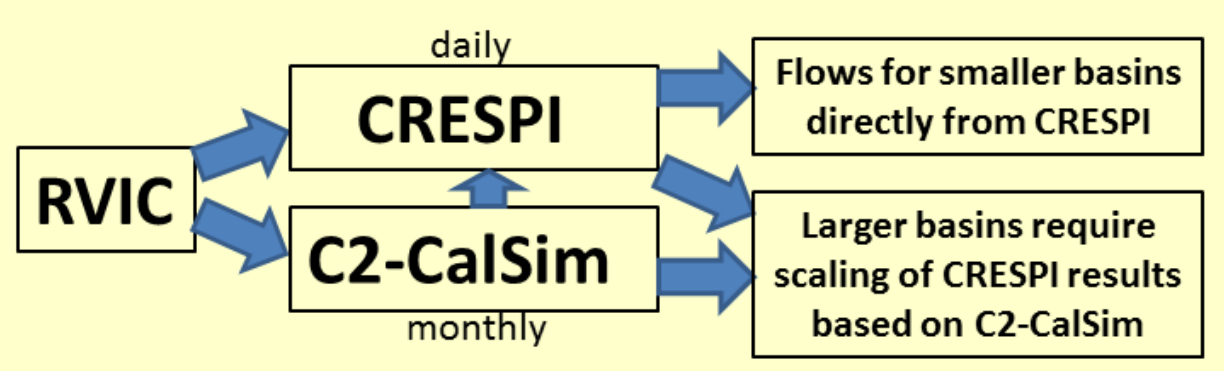

Figure 3. Flowchart showing the modeling of managed daily flows at points throughout the San Francisco Bay and Sacramento-San Joaquin Delta (Bay-Delta) watershed, California. GCMs, global climate models; LOCA, localized constructed analogs; VIC, Variable Infiltration Capacity hydrologic model; RVIC, VIC routing model; CASCaDE2, Computational Assessments of Scenarios of Change for the Delta Ecosystem phase 2; CRESPI, CASCaDE2 resampling algorithm; C2-CalSim, CASCaDE2 modified CalSim (California Department of Water Resources operations model).

The unimpaired streamflow estimates were next translated into managed flows using a combination of two methods. First, the freshwater management operations model developed jointly by the California Department of Water Resources and the U.S. Bureau of Reclamation, CalSim 2, was modified as described in section 4 of this report. The resulting model, which we call C2-CalSim (for CASCaDE2 modified CalSim), was driven by inputs derived from the RVIC unimpaired flows. This produced corresponding estimates of monthly averaged managed streamflows at outflow points of larger basins throughout the watershed. An algorithm to estimate daily managed flows, CRESPI (for CASCaDE2 resampling), was implemented using RVIC and C2-CalSim outputs as inputs. CRESPI produces daily flow estimates by drawing from recent historical flow patterns and using the other models' outputs to drive the pattern selection process. CRESPI's strength lies in its representation of daily flows (as opposed to C2-CalSim's monthly time scale). However, because CRESPI is limited to the historical flow regime, the resulting estimates of daily managed flows do not always faithfully represent the likely response of freshwater operations to long-term trends in flow patterns associated with long-term meteorological trends (manifestations of climate change) present in the GCM outputs. For smaller basins, this was not considered an important shortcoming, primarily because the contribution of those basins to the overall sediment and flow budgets of the entire Sacramento River Basin is relatively small (there were no smaller basins in the San Joaquin watershed studied in CASCaDE, just the watershed's total outflow). Also, smaller basins are typically not represented in C2CalSim; therefore, for smaller basin outflows, the CRESPI results were used directly. For larger basins, however, it was necessary to scale the CRESPI output to more closely represent the response of operations to long-term trends as represented in the C2-CalSim output. This scaling was the last step in the translation of daily meteorological quantities projected by CMIP5 GCMs into corresponding projections of managed daily flows at points throughout the Bay-Delta watersheds. Each of the steps of this procedure is discussed in more detail below. 


\section{RVIC Unimpaired Streamflow Simulations and Postprocessing}

\subsection{Overview of RVIC in CASCaDE2}

RVIC is a streamflow routing model designed to accept gridded VIC outputs and generate daily, unimpaired streamflow estimates at prescribed points on streams and rivers. The RVIC model was set up over the California-Nevada domain (corresponding to the domain of the VIC runs) and configured to produce streamflow estimates at the numerous locations throughout the Bay-Delta watershed needed for the CASCaDE2 project. For each of these locations, this process included determining the grid cells of the VIC hydrology model contained in the associated drainage basin (much of the RVIC configuration involved GIS software). The RVIC model takes as input gridded daily surface and subsurface flow contributions from each drainage basin's VIC grid cells and determines the resulting daily flow rate at the corresponding downstream outflow location by solving the shallow water equations to simulate the routing of the streamflow contributions to the outflow point. included:

Streamflows were simulated by RVIC for subsequent use in other model components. These

- 16 locations for producing boundary conditions for the watershed sediment model,

- 6 locations for producing D-Flow FM inflow boundary conditions,

- 10 locations for use in generating multiple C2-CalSim water-year indexes (discussed in sections 3.2 and 4.3),

- 33 locations for use in generating monthly inflows to drive C2-CalSim scenario runs (discussed in section 3.3), and

- 1 location (Shasta Lake inflow) for use in computing Shasta Lake target storages as part of the algorithm to convert C2-CalSim monthly outputs to daily flows (discussed in section 5.2.2.1.1). With some overlap between locations needed for different purposes, daily unimpaired streamflow time series at 57 locations were produced. This was done for each of the 20 GCM scenarios for the period 1950-2099 (10 GCMs $\times 2$ emissions scenarios). Additionally, a historical (1950-2013) "baseline” run of RVIC was performed by using VIC output driven by the gridded, observation-based meteorological dataset produced by Livneh and others (2015).

\subsection{Bias-Correcting RVIC Unimpaired Flows for Use in Producing C2-CalSim Water-Year Indexes}

Once these unimpaired flow estimates were produced, additional processing was needed. The historical baseline VIC output (routed with RVIC) generally compares favorably with observation-based unimpaired streamflow estimates (fig. 4). 


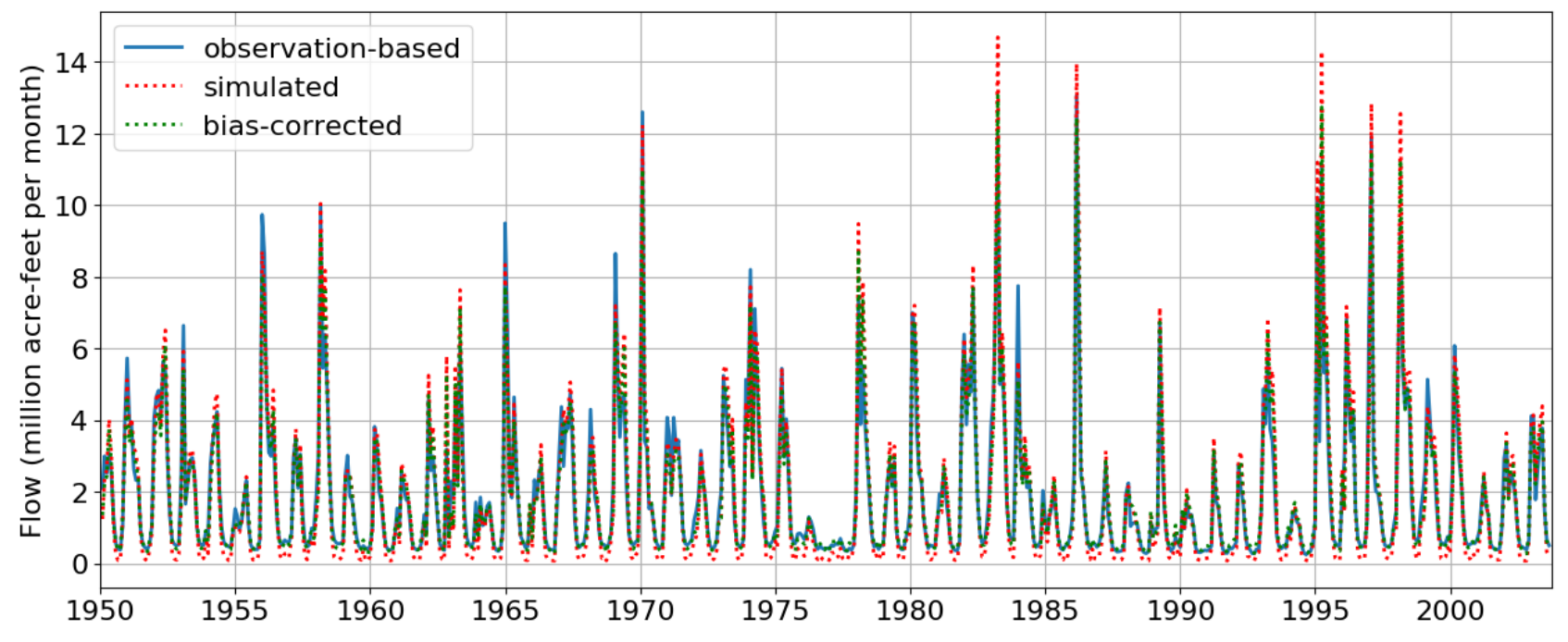

$A$

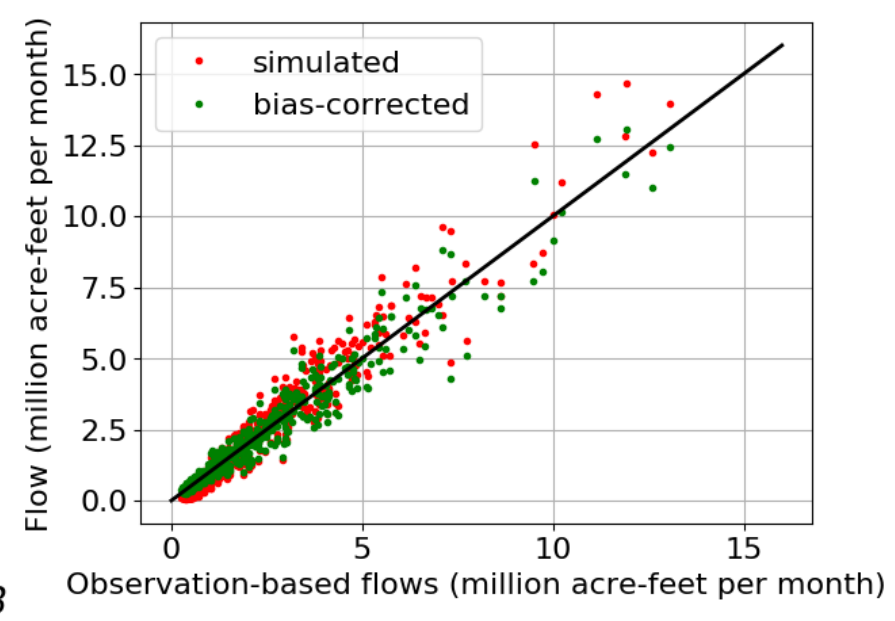

Figure 4. Graphs showing $(A)$ observation-based, simulated by the Variable Infiltration Capacity hydrologic model plus Variable Infiltration Capacity routing model $(\mathrm{VIC}+\mathrm{RVIC})$, and bias-corrected unimpaired Sacramento River Basin, California, total monthly flows, and $(B)$ simulated and bias-corrected flows versus observation-based flows. A one-to-one line, corresponding to perfect agreement, is shown in black. Unimpaired flow estimates are from California Department of Water Resources (2014).

Because this implementation of the VIC model is largely uncalibrated, there are some systematic errors in its output; these must be corrected when accurate unimpaired flow estimates are required. In particular, low flows are underestimated and high flows are overestimated by the VIC model (fig. 4B).

More accurate unimpaired flow estimates at the monthly scale were needed at 10 of the RVIC streamflow output sites to generate water-year indexes used by the C2-CalSim model (discussed in section 4.3). To achieve this, a quantile-mapping bias correction (QMBC) was applied to the RVIC streamflow outputs.

To apply QMBC, unimpaired flow time series for a historical period, assumed to be accurate, are needed for reference. Monthly unimpaired flow data (California Department of Water Resources, 2017) were obtained for all 10 locations used in the calculation of water-year indexes needed for C2-CalSim. At each flow location, the simulated historical baseline flows (based on the Livneh and others meteorology dataset [2015]) for the time period covered by the reference data were extracted and paired with the reference data. 
The QMBC method consists of, for each flow location, first estimating values that correspond to regularly spaced quantiles of the empirical cumulative distribution functions (CDFs) for that location's pair of historical simulated and reference time series (20 quantiles are used in this study). Then, using simulated future-scenario time series, a quantile is generated for each simulated daily flow value by interpolating the flow values corresponding to the two nearest mapped quantiles. Next, the biascorrected flow value, corresponding to the same quantile in the reference data, is determined by interpolating between the two nearest quantiles in the reference data $\mathrm{CDF}^{3}$. Finally, any peak flows in the future scenarios that exceed the highest flow produced in the baseline simulated flows (which corresponds closely to the highest quantile) were mapped by adding to them the difference between the highest quantile's flow value for the reference data and the corresponding flow value in the baseline simulation. In this way, the entire simulated future-scenario time series is bias-corrected (see example of bias-corrected historical flows in fig. $4 A-B$ ). If this bias correction were applied to the same historical simulated flow data used to generate the mapping (instead of to the future simulated flows), the empirical CDF of the resulting corrected time series would match that of the reference data. This approach assumes that biases in the historical simulation remain the same in future simulations.

Methods of bias-correction that are more sophisticated than QMBC are difficult to implement in the current application due to the prohibitively small length of available unimpaired monthly flow estimates (Boé and others, 2007). In the future, we may explore approaches to bias-correcting future scenarios that preserve changes in statistical moments relative to current climate (for example, Li and others, 2010, and Pierce and others, 2015).

Application of QMBC to GCM precipitation output has been shown to have the potential to alter trends relative to the uncorrected data (Maurer and Pierce, 2014). The effects of QMBC on trends in simulated streamflow are unclear. Because the bias-corrected data are to be used here as monthly averages to calculate indexes that largely portray broad annual flow categories, the importance of this shortcoming should be minimal.

\subsection{Transforming Unimpaired RVIC Flows to Managed Flows for Use as C2-CalSim Flow Inputs}

The RVIC outputs needed to generate altered C2-CalSim flow inputs for historical baseline and future-scenario C2-CalSim runs required transformation based on historical CalSim 2 input data, which represent impaired flows at the model's boundary points. To generate C2-CalSim inputs for future scenarios, a mapping was developed between historical baseline RVIC outputs (calendar years 19502013, based on the Livneh and others [2015] data) and CalSim 2 inputs representing impaired inflows from upstream basins (assuming modern infrastructure and freshwater demands in those basins for the whole time period). These impaired-inflow inputs to CalSim 2 were produced by the California Department of Water Resources for the period covering WYs 1922-2003. The mapping was developed for 33 locations representing nearly all of the freshwater input to CalSim 2 (table 1) using the WYs contained in both datasets: 1951-2003.

The mapping between the 33 RVIC output and CalSim 2 input time series was again achieved using QMBC (as described in section 3.2), except that in this case, separate mappings were developed for each location for each quarter of the calendar year. This refinement was added because unlike the previous flows mapped using QMBC, wherein fairly consistent systematic biases of the VIC and RVIC models were being corrected, the mapping here is translating from unimpaired flows to impaired flows

\footnotetext{
${ }^{3}$ For the software used - the qmap package in R-it was necessary to subtract the minimum flow of simulated and reference time series (that is, the minimum of both time series concatenated together) from both time series to avoid spurious zeros in the results.
} 
in the rim basins. Because management goals for most reservoirs vary by season, seasonal mappings are more appropriate than a single mapping for all seasons. Once the quantile maps were developed for each location based on the WY1951-2003 historical datasets, the maps were applied to the future-scenario RVIC outputs to generate the corresponding C2-CalSim inputs for these scenarios.

\section{Simulating Managed Streamflows Using C2-CalSim}

\subsection{CalSim 2 Description}

The mapped inflows described in section 3.3, along with meteorological data (discussed in section 4.3) extracted from the climate-change-scenario downscaled meteorology and historical baseline meteorology datasets (Livneh and others, 2015), were used to drive modified version of a model of freshwater management operations - the California Department of Water Resources' CalSim 2 model (Draper and others, 2004). CalSim 2 is a management optimization model in which, given inputs of reservoir inflows and other inflows, a set of freshwater management decisions that optimally satisfy operational goals and constraints is computationally determined on a monthly time step. The results are estimates of monthly managed freshwater flows at points throughout the watershed. CalSim 2 has been applied in other climate change studies (Brekke and others, 2004, 2009; Dracup and others, 2005; Vicuna and others, 2007; Anderson and others, 2008).

Prior applications of CalSim 2 outside of the CASCaDE2 project have been based on a fixed, historically based pattern of hydrologic variability. The period of these studies has generally begun with WY 1922 and, for most relatively recent studies, has ended with WY 2003. The freshwater management infrastructure and level of development (corresponding to projected population and agricultural irrigation needs) are static over the course of a CalSim 2 run, and the inflows over the historical period are taken to represent the range of hydrologic variability present in the watershed. Climate studies involving CalSim 2 typically apply monthly flow "perturbation" ratios to the standard historical input time series. These ratios encapsulate climatological monthly flow changes over time based on separate, typically GCM-driven, hydrological model runs. The main limitation of this approach is that the range and types of hydrologic variability represented are limited to the recent historical hydroclimatic regime. So, for example, 1983 is an unusually wet year in every run, as is 1998, and 1977 is always a very dry year and is always followed by a very wet 1978. Possible patterns of interannual and interdecadal variability other than those observed in WYs 1922-2003, such as those present in GCM runs, are therefore not evaluated in the traditional application of the CalSim 2 model. This is an important limitation because such relatively recent historical variability necessarily constitutes a limited subset of the possibilities inherent in the climate system, particularly as greenhouse gas concentrations continue to increase.

\subsection{Modification of CalSim 2 for CASCaDE2}

The CASCaDE2 project is designed to directly use downscaled, daily GCM output to drive models of the Bay-Delta estuary and watershed to assess the response of these systems not only to longterm meteorological trends, but also to changes in multiyear variability such as droughts and wet years and changes in the frequency and magnitude of even shorter term events such as extreme floods. The traditional application of CalSim 2, which uses static historically based hydrologic data, therefore does not meet CASCaDE2 project needs. The chosen solution was to modify CalSim 2 to accept dynamic hydrology. By "dynamic hydrology," we mean sequences of inputs not constrained to historical sequences, generated directly from hydrologic model output. Although traditional CalSim 2 runs cover 
WYs 1922-2003 with some runs ending a few years later, the CASCaDE2 implementation of CalSim 2, C2-CalSim, simulates WYs 1980-2099. The start date of WY 1980 was chosen because most large modern freshwater management infrastructure in the Bay-Delta watershed was constructed and filled by that time, so reasonable comparisons between simulated and observed managed flows may be made from WY 1980 onward.

CASCaDE2 includes assessment of potential impacts of a massive proposed infrastructure project that involves the construction of one or more tunnels under the Delta as an alternative means of conveying freshwater from the Sacramento River to the export pumps in the south Delta. The current version of this plan is called “California WaterFix.” The predecessor to WaterFix was called the BayDelta Conservation Plan (BDCP). The California Department of Water Resources (CDWR) configured CalSim 2 to include the operations of the proposed tunnels and used the model to conduct evaluations of the BDCP's impact. These BDCP CalSim 2 configurations were publicly available, so we used them as the starting point for our C2-CalSim modeling. The model files were obtained from the California Department of Water Resources, and of the model configurations used to evaluate alternatives for the BDCP, two were chosen for use in CASCaDE2. The "No-Action Alternative with Fall X2 management” (referred to subsequently as NAA) was chosen as our scenario representing minimal inDelta infrastructure change (chapter 3, section 3.5.1 in California Department of Water Resources and U.S. Bureau of Reclamation, 2016), and the “Alternative 4 with decision tree," the California Environmental Quality Act preferred alternative (PA), was chosen as our "alternative conveyance” scenario (chapter 3, section 3.5.9 in California Department of Water Resources and U.S. Bureau of Reclamation, 2016). Another configuration developed for the BDCP study was an "Existing Conditions" (EC) run, which used the standard historical CalSim 2 inputs, unaltered for climate change. Time series for 33 of the "Existing Conditions" inputs were extracted and used in developing the quarterly QMBC mapping between historical baseline RVIC outputs and historical CalSim 2 inputs, described in section 3.3. All other input time series from the "Existing Conditions" CalSim 2 configuration were extracted for use in the resampling approach to the generation of future-scenario versions of these inputs (described in section 4.4).

The BDCP studies evaluated these and other alternatives by using a perturbation ratio approach to modify historical CalSim 2 inputs. The perturbation ratios were derived from VIC runs driven by downscaled GCM outputs whose trends in precipitation and temperature over the study region fell near the medians of trends among select members of the Coupled Model Intercomparison Project Phase 3 GCM ensemble. The individual CalSim 2 inflow inputs that were modified in this manner to represent climate change are shown in appendix 5A, section D.3.4 of California Department of Water Resources and U.S. Bureau of Reclamation (2016) and are reproduced in part in table 1. Locations of the creeks and rivers referenced in table 1 are shown in figure 5. 
Table 1. Locations in San Francisco Bay and Sacramento-San Joaquin Delta (Bay-Delta) watershed, California, of CASCaDE2 modified CalSim (California Department of Water Resources' operations model) (C2-CalSim) inflow boundary conditions that are derived from global climate model driven Variable Infiltration Capacity routing model (RVIC) daily flow estimates.

[Location numbers are shown in figure 5] Rim-basin inflows

1. Trinity Lake Inflow

2. Lewiston Lake Inflow

3. Shasta Lake Inflow

4. Black Butte Lake Inflow

5. Lake Oroville Inflow

6. Folsom Lake Inflow

7. New Hogan Lake Inflow

8. New Melones Lake Inflow

9. New Don Pedro Lake Inflow

10. Lake McClure Inflow

11. Eastman Lake Inflow

12. Hensley Lake Inflow

13. Millerton Lake Inflow

\section{Basin floor inflows}

14. Clear Creek Inflow to Sacramento River

15. Cottonwood Creek Inflow to Sacramento River

16. Cow Creek Inflow to Sacramento River

17. Battle Creek Inflow to Sacramento River

18. Paynes Creek Inflow to Sacramento River

19. Red Bank Creek Inflow to Sacramento River

20. Antelope Creek Inflow to Sacramento River

21. Mill Creek Inflow to Sacramento River

22. Deer Creek Inflow to Sacramento River

23. Elder Creek Inflow to Sacramento River

24. Thomes Creek Inflow to Sacramento River

25. Big Chico Creek Inflow to Sacramento River

26. Butte Creek Spills to Sutter Bypass

27. Stony Creek Inflow to Stony Gorge Reservoir

28. Little Stony Creek Inflow to East Park Reservoir

29. Kelly Ridge Inflow to Feather River

30. Yuba River Inflow to Feather River

31. Bear River Inflow to Feather River

32. Cosumnes River Inflow to Delta

33. Mokelumne River Inflow to Delta 


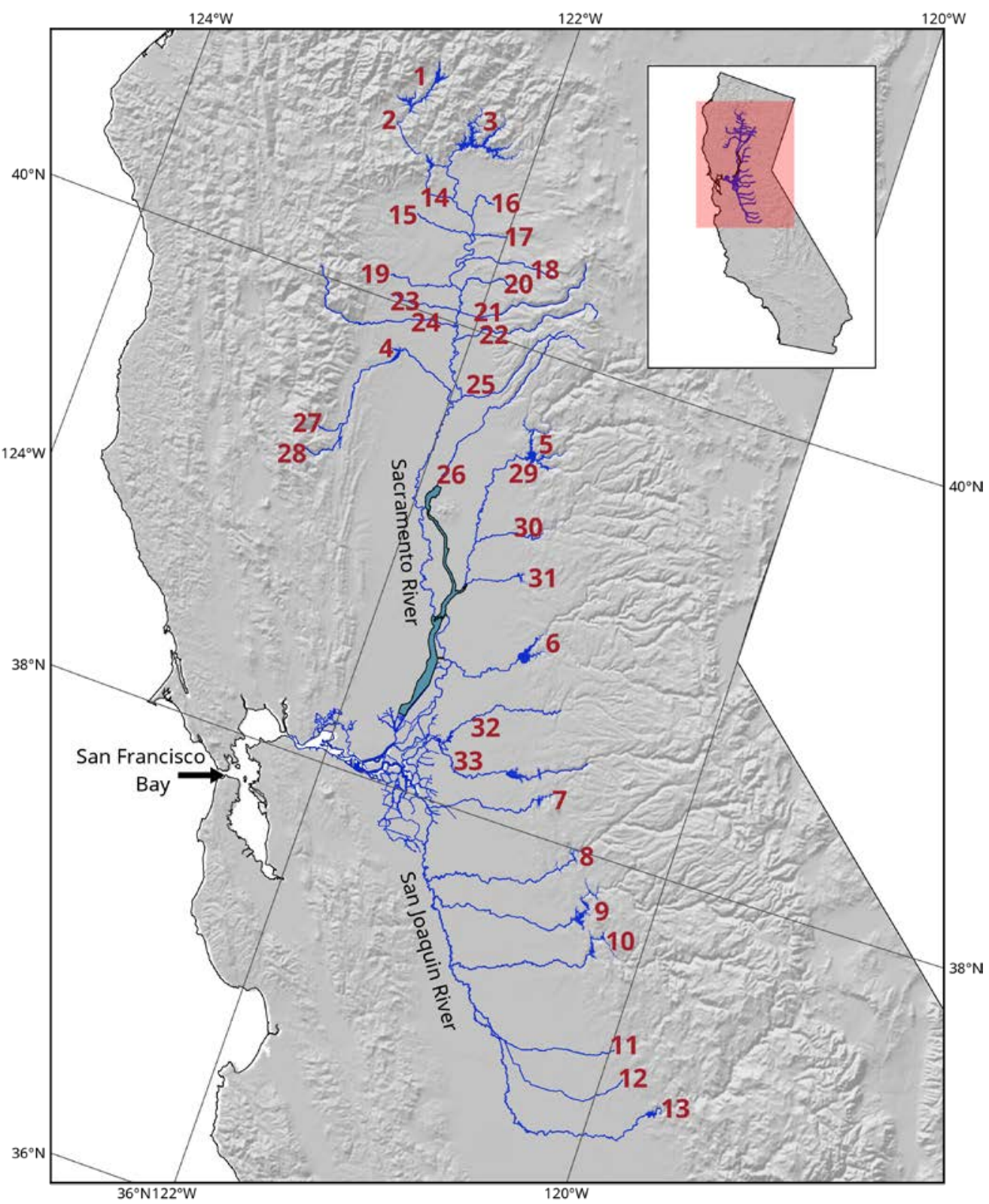

Figure 5. Map showing major creeks and rivers in the San Francisco Bay and Sacramento-San Joaquin Delta (Bay-Delta) watershed, California, corresponding to CASCaDE2 modified CalSim (California Department of Water Resources' operations model) (C2-CalSim) inflow boundaries. See table 1 for names of features. Base map sources: U.S. Geological Survey and Esri.

For CASCaDE2, these same inflow inputs were replaced with the values for future scenarios generated with the quarterly QMBC approach described in section 3.3. All other time-varying CalSim 2 inputs were also modified based on future-scenario VIC and RVIC outputs (see sections 4.3 and 4.4). Running the C2-CalSim model with these input changes required multiple modifications to the CalSim 2 configuration files. The modifications included the following steps, which are automated in Bash or Python scripts:

1. All model files for a given alternative were extracted to a temporary folder.

2. Pathnames were corrected so C2-CalSim could run on the local file system. 
3. Dates in the CalSim 2 initial conditions file were modified to implement a WY 1880 start date (as opposed to the usual WY 1922 start date). Note that due to technical limitations of CalSim 2, the nominal run period for future scenarios is WYs 1880-1999, rather than WYs 1980-2099. Only the dates reflect this difference; all other data correspond to the future scenario.

4. All beginning and ending dates in model configuration ("wresl") files were changed to reflect the WY 1880-1999 run time.

5. A new model input parameter, "WYORIG," was implemented in the configuration and input files. This input was needed to make the resampling approach described in section 4.4 work with the neural network library used to estimate salinities in the Delta.

\subsection{Calculation of Indexes Used in C2-CalSim}

Next, some pre-processing was needed to generate time series of key annual indexes needed as input to future-scenario C2-CalSim runs. Except where otherwise indicated, these various indexes are independent, serve distinct purposes in freshwater management and the CalSim 2 model, and bear no quantitative relation to one another. The first index described below is based on meteorological data, and the remaining indexes were derived using the bias-corrected unimpaired flows discussed in section 3.2. These indexes are used (in practice and in CalSim 2) in a range of water allocation decisions. Most indexes were defined in water-resource management agency documents (for example, State Water Resources Control Board, California Environmental Protection Agency, 1995, 1999).

Brief descriptions of these annual indexes and their derivations are listed here:

1. The U.S. Fish and Wildlife Service biological opinion “Action 3" smelt temperature threshold crossing date is the annual date on which the average of water temperatures at specific sites within the Delta first rises above the critical threshold of 12 degrees Celsius $\left({ }^{\circ} \mathrm{C}\right)$ (U.S. Fish and Wildlife Service, 2008). When this threshold is exceeded, specific flow restrictions are implemented in CalSim 2. In this calculation, monthly mean air temperatures at the Sacramento Executive Airport are assumed to be identical to the water temperatures, as in the BDCP study (Appendix 5A, section B in California Department of Water Resources and U.S. Bureau of Reclamation, 2016). These air temperatures were extracted for future scenarios from the downscaled climate-change scenarios for the grid cell containing the airport. As in the BDCP study, monthly mean values were assumed to occur in the middle of the month, and daily data were interpolated between these values to obtain the day and month of the first ascending smelt temperature threshold crossing in each WY. These dates typically were in the months of February-April. Frequently, in the warmer climates of several of the future scenarios, the resulting water temperature estimates were never below the $12{ }^{\circ} \mathrm{C}$ threshold. In those cases, the date of December 1 was used as the smelt temperature threshold crossing date.

2. The Sacramento River WY type index is based on the total unimpaired Sacramento River Basin flow. The index is calculated as follows. First, the following expression is evaluated:

$(0.4) \times$ current Apr-Jul runoff forecast (in million acre-feet) $+(0.3) \times$ current Oct-Mar runoff (in million acre-feet) $+(0.3) \times$ previous WY's index (if the previous WY's index exceeds 10.0 , then 10.0 is used).

Then, based on this calculated value, the index is assigned one of the following integer values (qualititative descriptions of the corresponding WY are in parentheses):

1 (Wet): Equal to or greater than 9.2

2 (Above normal): Greater than 7.8, and less than 9.2

3 (Below normal): Greater than 6.5, and equal to or less than 7.8 
4 (Dry): Greater than 5.4, and equal to or less than 6.5

5 (Critically dry): Equal to or less than 5.4

3. The Oct-Mar Sacramento River index is just the Oct-Mar total Sacramento River Basin outflow in million acre-feet.

4. The San Joaquin River WY type index is similar to the Sacramento River WY type index, but with a different calculated value:

(0.6) $\times$ current Apr-Jul runoff forecast (in million acre-feet) $+(0.2) \times$ current Oct-Mar

runoff (in million acre-feet) $+(0.2) \times$ previous WY's index (if the previous WY's index

exceeds 4.5 , then 4.5 is used).

Based on this calculated value, the index is assigned as:

1 (Wet): Equal to or greater than 3.8

2 (Above normal): Greater than 3.1, and less than 3.8

3 (Below normal): Greater than 2.5, and equal to or less than 3.1

4 (Dry): Greater than 2.1, and equal to or less than 2.5

5 (Critically dry): Equal to or less than 2.1

5. The "SJRAve5" index for a given year is the average of the San Joaquin River WY type index for the 5 previous WYs.

6. The Shasta WY index has a more complicated logic; refer to the calc_indexes.py code for details.

7. The "AmerD893" index is based on the Apr-Sept total unimpaired American River flow in thousand acre-feet. The index has a value of 1 if the AmerD893 index is greater than 600,000 acre-feet (acre-ft) and a value of 2 otherwise.

8. The Feather River index has a complicated logic similar to the Shasta WY index. Refer to the calc_indexes.py code for details.

9. The Trinity River index is based on unimpaired Trinity River flows. The index values are assigned as follows:

If flow is:

less than 650,000 acre-ft, index is 5;

greater than or equal to 650,000 acre-ft and less than 1,025,000 acre-ft, index is 4; greater than or equal to 1,025,000 acre-ft and less than 1,350,000 acre-ft, index is 3; greater than or equal to 1,350,000 acre-ft and less than 2,000,000 acre-ft, index is 2; greater than 2,000,000 acre-feet, index is 1 .

10. The Eight-River index is the total unimpaired Sacramento and San Joaquin River flows, in thousand acre-feet.

11. The Delta index is the sum of the Jan-May unimpaired Sacramento and San Joaquin River flows, in thousand acre-feet.

\subsection{Resampling of Remaining Standard CalSim 2 Inputs}

With the indexes described in section 4.3 and the major C2-CalSim inflows (table 1) derived from GCM-driven RVIC flows generated for all scenarios and for the historical observation-based Livneh dataset (Livneh and others, 2015), all remaining C2-CalSim inputs were generated for the historical baseline and future-scenario runs by resampling the corresponding inputs from the standard input files of the BDCP scenario being evaluated (that is, EC before 2030, or NAA or PA after 2030).

The resampling steps are as follows:

1. Total monthly rim-basin inflows were calculated as the sum of monthly flows over all rim basins (table 1). These were calculated using the "Existing Conditions" study inputs and the quarterly 
QMBC-mapped C2-CalSim inflows (described in section 3.3) for the historical baseline and future scenarios.

2. For each water year in the historical baseline and the future scenarios, a best-match year was selected from the "Existing Conditions" rim-basin inflows, where the match metric was determined as:

$$
\begin{aligned}
& C_{y}=\sqrt{\frac{\frac{1}{12} \sum_{m=1}^{12}\left(Q_{m}-T_{y, m}\right)^{2}}{\bar{Q} \bar{T}}} \\
& P_{y}=\left|\frac{\frac{1}{12} \sum_{m=1}^{12}\left(Q_{m}-T_{y-1, m}\right)}{\frac{1}{2}(\bar{Q}+\bar{T})}\right| \\
& d_{y}=C_{y}+P_{y} / 25,
\end{aligned}
$$

where

$Q_{m} \quad$ is total rim-basin flow for a given month ( $m$, where $m=1$ indicates the first month in the WY) in the WY to be matched in the historical baseline or future scenario;

$T_{y, m} \quad$ is total rim-basin flow for a given month $(m)$ in the candidate matching WY $(y)$; calculated using rim-basin flows extracted from the "Existing Conditions" study;

$\bar{Q}$ and $\bar{T}$ are the long-term mean of the total rim-basin flows from the historical baseline or future scenario and the long-term mean from the "Existing Conditions" study inputs, respectively;

$C_{y}$ and $P_{y}$ are metrics for current water-year flows and previous water-year flows, respectively; and

$d_{y}$ is the combined metric, with the coefficient $1 / 25$ chosen through an iterative "leave-one-out" cross-validation (described below) to optimally represent the combined effects of current water-year flows and previous water-year flows on the CalSim 2 inputs being resampled. The previous water-year flows are included mainly to represent reservoir carry-over storage.

3. All C2-CalSim inputs, other than the 33 inflows and the 11 indexes derived directly from RVIC streamflows, for the water year being matched in the historical baseline or future scenario are filled with the corresponding inputs from the best-match year (year with minimum $d_{y}$ ) in the standard input files of the BDCP scenario being evaluated (EC for years before 2030, or NAA or PA after 2030).

Steps 1-3 are repeated until the C2-CalSim inputs for all 34 years of the historical baseline (WYs 19802013) and 120 years of each future scenario (WYs 1980-2099) have been produced.

Coefficient selection for the metric $d_{y}$ was carried out by applying the procedure described above but using only the EC dataset. The rim-basin inflows for each WY in the EC dataset (WYs 1922-2003) were used to select a best-match WY from all other years in the EC dataset (eqs. 3-5). The C2-CalSim inputs described in step 3 above from the best-match WY were pulled from the EC dataset to fill the corresponding values for the year being matched. This "leave-one-out" procedure was applied to all years in the EC dataset, resulting in a cross-validation dataset that was then compared to the original EC 
dataset. Evaluation of goodness-of-fit between the two datasets over a range of coefficient values resulted in the metric shown in step 2 above.

A record of which water years were selected as best matches for each scenario are also retained and added to the C2-CalSim inputs files as values for the WYORIG input variable. CalSim 2 calls a separate artificial neural network (ANN) algorithm to generate estimates of salinity and salinity-related quantities based on a range of inputs. One of the ANN inputs is the current water-year value. Because the ANN is a binary software library that was trained using WYs 1922-2003, the ANN calls in the C2CalSim configuration files were altered to use WYORIG (which still varies from 1922 to 2003) instead of the model run's current water-year value, which varies from 1980 to 2099 in C2-CalSim. In this way, the resampling approach described here extends to this aspect of the ANN calls.

\subsection{Sequential Execution of C2-CalSim Studies}

Several factors define a given C2-CalSim run. The first is which study is being evaluated: EC, NAA, or PA. For CASCaDE2, the EC model configuration is used to represent WYs 1980-2029 (recall that for the GCM-derived scenarios, the "historical” period does not correspond to observed historical behavior). The NAA and PA studies are used for WYs 2030-2099. This assumes the management changes represented in the NAA and PA studies are not put into effect until WY 2030. Another factor that affects a given C2-CalSim run is the level of development (LOD), represented as freshwater demands corresponding to future projections of population and land use. The EC configuration uses an LOD corresponding to the year 2005, and the NAA and PA configurations use a 2030 LOD. Thus, 2030 seemed an appropriate transition date between model configurations, because of the available LODs and the likelihood that any major infrastructure changes (for example, Delta tunnels) would not be completed for at least another decade. In the transition from the EC to the NAA or PA studies at 2030, the NAA and PA studies were started in 2020 and allowed 10 years to spin up, and the spin-up period was discarded. Similarly, the EC portion of the sequence (WYs 1980-1929) was allowed to spin up for 10 years, and the outputs for WYs 1970-1979 were discarded.

A final factor that should have been included in defining a given study, but in the end was not, was the sea level rise (SLR) value used. Because salinities resulting from given inflow patterns increase with SLR, more flows are required to meet salinity standards as sea level increases (Anderson and others, 2008; Van Lienden and others, 2014). CalSim 2 uses an ANN to estimate salinity and salinityrelated quantities at points throughout the Delta (Chung and Seneviratne, 2009). For the BDCP studies, this ANN was trained for conditions corresponding to SLR amounts of 0 centimeters (cm), $15 \mathrm{~cm}, 30.5$ $\mathrm{cm}$ (1 foot [ft]), and $45 \mathrm{~cm}$, resulting in four separate ANNs that could, in theory, be used in a given C2CalSim study. Many attempts were made to incorporate the different ANNs into the present study to approximate the effects of projected SLR in each scenario on salinity throughout the Delta. These attempts were abandoned, however, due to apparent software incompatibilities between the ANN binaries and the various configurations of C2-CalSim employed in this study. The ANN corresponding to no SLR was used in every case. As SLR increases in a given scenario, the resulting C2-CalSim outputs will therefore underestimate the flows required to meet salinity standards, and with regard to this aspect of management at least, represent a more optimistic water-management scenario than is likely. We may revisit this issue in the future. However, until ANNs are available for much larger amounts of SLR (at least $100 \mathrm{~cm}$ ), even a successful implementation of this approach will significantly underestimate the flows needed to repel salinity. See section 4.7 for further discussion of this. 


\subsection{Automating C2-CalSim Runs}

With the BDCP study CalSim 2 configuration suitably modified and the C2-CalSim inputs for the historical baseline run and for all future-scenario runs generated, and with run segments configured to allow for variation in management infrastructure and strategies (as represented in the different BDCP studies) and for some variation in LOD, the next step was to run C2-CalSim. Execution of all 20 future scenarios and the historical baseline run was automated using Bash, Python, and HEC-DSS Jython scripts on Linux, combined with a Windows virtual machine with Cygwin OpenSSH, AutoIt, and WRIMS 1.3.0 (the underlying software on which the CalSim 2 model is run) installed.

Initially, the C2-CalSim runs crashed when a particular combination of inputs and state variables occurred. This most commonly occurred during very low inflows, though it occasionally occurred during very high inflows. It was prohibitively difficult to diagnose these crashes on a case-by-case basis, so we decided to moderately increase (or decrease, in the rare cases where the crash was during high flows) all inflows listed in table 1 for the month of the crash and restart the run at the beginning of the water year during which the crash occurred. This process was automated, successively increasing (or decreasing) the crash month's flows until the run was successful or a limit imposed on the multiplicative factor being applied to the flows was reached. In the case of only six individual months out of all scenarios run, this approach still did not prevent the crash, and a fallback solution of replacing the crash month's inflows with inflows from the same month in the previous water year was implemented. In this way, all C2-CalSim runs were completed. In nearly all cases, this approach is nudging extreme flows to be slightly less extreme, so the overall effect on results is small. The average number of months (over all scenarios) whose inflows were altered in this manner was 15 months out of 1,440 over the 120-year scenario. The scenario with the most altered months was GFDL-CM3/RCP8.5, which had 35 altered months. Averaged over all WYs in a scenario, the maximum (among scenarios) resulting alteration in WY-total flow was 0.5 percent, for the GFDL-CM3/RCP8.5 scenario. Averaged over all scenarios, flows were altered 0.2 percent.

Finally, all needed flows, diversions, operational time series, and storages were extracted from the resulting output files. Time series extracted from the C2-CalSim runs are as follows:

- Reservoir storages: Shasta, Oroville

- Reservoir outflows: Oroville, Keswick, Black Butte Dam, Nimbus, Camp Far West, Whiskeytown

- Flows at these locations: Cosumnes, Vernalis, Verona, Yolo Bypass

- Exports: Tracy and Banks pumping plants, North Bay Aqueduct, Rock Slough (Contra Costa Water District [CCWD]), Old River+Victoria Canal (CCWD), BDCP “isolated facility” tunnel intake (only used in the BDCP PA scenario)

- Other operations: Sacramento Weir flow, number of days per month that C2-CalSim simulated the Delta Cross-Channel gates as being open

All steps above were completed for the EC $\rightarrow$ NAA sequence, which will provide flows for the CASCaDE2 climate-change-only scenarios, and for the EC $\rightarrow$ PA study, which will provide flows for the CASCaDE2 alternative conveyance scenarios.

\subsection{Application of C2-CalSim in CASCaDE2: Limitations and Future Work}

In attempting to represent the future behavior of a complex freshwater management network like California's, several difficulties are encountered. Projecting freshwater demands is difficult, and for CalSim 2, demand scenarios were only available for California's LOD in 2005 (used in the BDCP EC study) and the LOD projected for 2030 (used in the PA and other BDCP studies). In CASCaDE2, all 
C2-CalSim runs use the 2005 LOD until the beginning of WY 2030, after which they use the 2030 LOD. This necessarily introduces errors into the results, with a key limitation being that projections well past 2030 almost certainly underestimate freshwater demands, barring major changes in California water-use patterns and (or) much lower population increases than are currently projected.

Another problem is that freshwater management infrastructure is not static. Representing the numerous historical infrastructure changes is difficult, and predicting future changes is impossible. The only infrastructure changes considered in CASCaDE2 are those inherent in the different infrastructure scenarios-for example, changes including new tunnels and a new notch in Fremont Weir in the PA configuration as opposed to a largely present-day infrastructure for the climate-change-only (NAA) scenarios. For a given scenario, the only changes in freshwater management infrastructure and management goals are those associated with the transition from the EC configuration to either the NAA or the PA configurations in WY 2030. The results may therefore be interpreted as potential changes that additional future adjustments to management infrastructure and goals beyond those represented here may be designed to help mitigate.

A limitation of CalSim 2 (and therefore of C2-CalSim) is its treatment of groundwater withdrawals, which are allowed in the model to occur at unsustainable levels if other supplies of freshwater are insufficient to meet demands. This must be considered when interpreting results. In particular, simulated unsustainable withdrawal levels are indicative of an inability to meet freshwater demands through other means.

A standard step in new applications of CalSim 2 is to "retrain" the Water Supply Index-Delivery Index (WSI-DI) curve for a given hydrologic regime and model configuration. The WSI-DI curve relates available water supply (represented by WSI) and deliveries and carryover storage (DI) for the State Water Project and the Central Valley Project. A procedure exists for optimizing this curve for a given set of inputs. A good description of the WSI-DI curve and the retraining is given in section 3.3.1 of California Department of Water Resources (2005). Initially, the plan for CASCaDE2 was to use the present-day WSI-DI curve for the baseline historical run and for WYs 1980-2019 in all future scenarios and to retrain WSI-DI separately for WYs 2020-2059 and 2060-2099 for each scenario. This would allow some amount of management "adaptation” to changing hydroclimatic conditions. However, the additional model runs involved in the retraining would have increased total model time by a factor of 7 , resulting in about a month of total C2-CalSim run time. This amount of additional time was considered prohibitive, and the resulting caveat is that calculated deliveries and carryover storage allocations may be suboptimal, particularly later in the future scenarios. Additionally, the intent of the CASCaDE2 C2CalSim runs is to explore implications of climate change on managed flows using current management infrastructure and strategy, and WSI-DI retraining would be counter to this intent.

Finally, the failure to include a representation of the effects of SLR in C2-CalSim was discussed in section 4.5. This results in an underestimation of Delta outflows required to repel saltwater in the dry season and an overestimation of the salinities in the corresponding hydrodynamical simulations. Separate CASCaDE2 work (Roseanne Martyr-Koller, University of California, Berkeley, written commun.) has resulted in hydrodynamical-model-based estimates of the amount of additional outflow needed to meet salinity standards for a range of future SLR values. These results complement the present work by quantifying additional outflows that would be needed to meet salinity standards under the 20 scenarios evaluated. However, additional work will be needed to understand the feasibility of the required additional reservoir releases, given the increasing tensions between supply and demand already depicted in the scenario evaluations. 


\section{CRESPI}

C2-CalSim produces monthly estimates of managed flows. For evaluations of estuarine hydrodynamics and ecological behavior being undertaken in CASCaDE2, we also need to represent daily flow variability. The CRESPI method, described in section 5.1, simulates daily managed flows by resampling from the historical record. In order to better simulate the effect of reservoir management on peak impaired flows, we partitioned the historical training data used by CRESPI. This partitioning was based on whether the reservoir storage was in a state of surplus or deficit. This modification, described in section 5.2.2, helps capture the tendency for high flows to occur when reservoirs are storing a surplus of water.

\subsection{Method}

In the CRESPI algorithm, at each location where daily managed flows were needed, we worked with time series of two streamflow variables: the unimpaired time series and the impaired time series. For the historical time series 1950-2013, we had observations of the impaired time series and simulations of the unimpaired time series. For the projected time period, we had only the unimpaired simulation. We used a resampling-based approach to generate the time series of the impaired variable based on the projected unimpaired time series. This approach involves sampling contiguous sections, or blocks, of the historical impaired time series and concatenating them to form an impaired time series for the projected period. The CRESPI algorithm can be divided into two steps. In the first step, a daily time series of the impaired variable is generated without considering dependence or continuity between adjacent blocks; in the second step, this time series is re-generated by considering neighboring daily values, allowing artifacts from the first step to be reduced.

\subsubsection{First Step: Matching Blocks}

The procedure for generating the projected impaired time series using the unimpaired time series $x$ is as follows. The algorithm steps through the projected time series month by month. For each month $m$ (which varies from 1 to the number of months in the series) of length $l$ (where $l$ can be 28, 29, 30, or 31, depending on the month and year) of the projected time series, the algorithm extracts the unimpaired time series $x\left(\boldsymbol{u}_{m}^{f}\right)$, where $\boldsymbol{u}$ is a vector of the time indexes for month $m$ in time series $f$ (for "future"). The algorithm then searches all blocks of $l$ days in the historical $(h)$ unimpaired time series for the $N_{b}$ most similar blocks $x_{i}\left(\boldsymbol{u}_{n}^{h}\right)$ where $n$ ranges from 1 to the number of $l$-day blocks in the historical time series and $i$ ranges from 1 to the predetermined value $N_{b}$. In CASCaDE2, a value of $N_{b}=30$ was chosen after some experimentation. Similarity is measured by the root mean square error between $x\left(\boldsymbol{u}_{m}^{f}\right)$ and $x_{i}\left(\boldsymbol{u}_{n}^{h}\right)$.

At this point, a monthly mean constraint can be imposed if available. In CASCaDE2, C2-CalSim projections of mean monthly flows were available at many locations of interest throughout the watershed. The following approach was tested: from among the $N_{b}$ similar blocks of daily data, the one whose mean best matches the constraint (that is, differs least from the C2-CalSim projection for the future month being matched) was selected as the optimal $x\left(\boldsymbol{u}_{n}^{h}\right)$. However, this additional restriction on the historical impaired data available for matching proved too restrictive and led to unacceptably high errors when evaluating historical results against observations. The monthly constraint option of the CRESPI method was therefore not implemented for CASCaDE2.

With no monthly constraint imposed, the most similar block according to the RMS (root-meansquare) measure described above is selected as the optimal $x\left(\boldsymbol{u}_{n}^{h}\right)$. When $x\left(\boldsymbol{u}_{n}^{h}\right)$ has been selected, the 
values of the simultaneous block of the impaired variable $y\left(\boldsymbol{u}_{n}^{h}\right)$ are copied and inserted into the projected time series to become the values of the impaired variable for the current month, $y\left(\boldsymbol{u}_{m}^{f}\right)$.

\subsubsection{Second Step: Smoothing Discontinuities}

In the first step (section 5.1.1), the daily time series is generated without considering the continuity or temporal dependence between adjacent blocks. As a result, time series generated in the first step may contain discontinuities at the block boundaries. We smooth these discontinuities by again selecting new patterns to estimate the impaired time series. We achieve this task by performing a procedure similar to the one described in section 5.1.1. By using the preliminary daily time series of the impaired variable for the projected time period generated in the first step, we can now search for the best-matching block of the impaired time series directly instead of assigning values to the impaired series based on the best match for the unimpaired series. In this step, we also include neighboring values of the block in the matching error metric in order to find patterns that are better associated with the temporal variability constructed during the first step. For example, for each month $m$ of with length $l$ days of the projected time series, the algorithm extracts the impaired time series $y\left(\boldsymbol{v}_{m}^{f}\right)$, where $\boldsymbol{v}$ is a vector of $2 k+l$ time indexes $-l$ for the month $m$ in the projected time series $(f)$ and $k$ days before and after month $m$. In the application of this method in CASCaDE2, $k=7$. That is, in this smoothing step, the matching block contains the month $m$, the 7 days preceding the month $m$ (the last 7 days of month $m-1$ ), and the 7 days following the month $m$ (the first 7 days of month $m+1$ ). The number of preceding or following days included is zero when estimating streamflow in the first or last month of the projected time series, respectively. Although the $k$ neighboring days are included in the match metric, they are discarded before inserting the matching block into the projected time series.

In this second step, any monthly constraint used in step 1 is not re-applied - the algorithm searches each block of $2 k+l$ days in the observed historical impaired time series for the single most similar block $y\left(\boldsymbol{v}_{n}^{h}\right)$; here, $n$ varies from 1 to the number of $2 k+l$-day blocks in the historical impaired

time series. Again, similarity is measured by the root mean square error between $y\left(\boldsymbol{v}_{m}^{f}\right)$ and $y\left(\boldsymbol{v}_{n}^{h}\right)$. This second step reduces discontinuities between adjacent blocks that may have been generated during the first step.

\subsection{Application to CASCaDE2}

The CRESPI method is applied individually to each of the points where managed flows are required. The unimpaired quantity is the routed streamflow generated by RVIC, and the impaired quantity is impaired streamflow at the same location (though the algorithm does not require the two quantities be collocated; just that they be strongly related as in upstream and downstream flows, for example,). The historical period used is the subperiod within January 1, 1950-December 31, 2013, in which the impaired data were observed and suitably representative of modern infrastructure. Where CRESPI is applied to a point downstream of either Lake Oroville or Shasta Lake, the historical training data are partitioned based on the observed storage minus the target storage, or the "storage excess," as described in section 5.2.2. The projection time period extends from the beginning of the calendar year 1950 to the end of calendar year 2099 or 2100, depending on the GCM scenario. After application of the CRESPI method, the time series were clipped to WYs 1980-2099, commensurate with the C2-CalSim results. 


\subsubsection{Historical Impaired Flow Data}

The historical impaired flow data on which the future CRESPI projections are based (table 2) come from the U.S. Geological Survey (USGS) National Water Information System (NWIS; U.S. Geological Survey, 2018. We used historical streamflow data starting from either 1950, the beginning of the record, or the date when major upstream impairments went into service, whichever was latest. For example, for points below major dams, we used data starting in the water year after the date that dams were completed. For some streamflow stations, such as station 11376150 (Eagle Canyon Canal Diversion), we set the cutoff date to points where the patterns of flow changed significantly in the record. In most cases, these stations were below the impairments. Because no suitable station could be identified downstream of Lakewood Dam, station 11425310 (Lakewood), above the dam, was used.

The cutoff date for the data used for the points farthest downstream (Vernalis, Verona, Yolo, and Freeport), was the beginning of calendar year 1970 because most of the major dams in the SacramentoSan Joaquin River Basin had been completed by then. Some dams were completed after 1970, the largest of these being New Don Pedro Dam in 1971 and New Melones Dam in 1979 (California Department of Finance, 2008), both in the San Joaquin River Basin.

For the impaired point located below Oroville/Thermalito, the sum of the data from stations 11406920 (Thermalito) and 11407000 (Oroville) was used.

Table 2. Streamflow station records from the San Francisco Bay and Sacramento-San Joaquin Delta (Bay-Delta) watershed, California, used as historical data in the Computational Assessments of Scenarios of Change for the Delta Ecosystem phase 2 (CASCaDE2) resampling algorithm (CRESPI) method.

[NWIS, National Water Information System database; Rec start, the beginning date of the record; Cutoff, the date before which data were excluded; Rec end, the ending date of the record; CDOF, California Department of Finance; YCWA, Yuba County Water Agency; CDWR, California Department of Water Resources]

\begin{tabular}{|c|c|c|c|c|c|}
\hline $\begin{array}{l}\text { NWIS site } \\
\text { number }\end{array}$ & $\begin{array}{l}\text { Station name } \\
\text { (upstream dam) }\end{array}$ & $\begin{array}{c}\text { Rec start } \\
\text { (year-month) }\end{array}$ & $\begin{array}{c}\text { Cutoff } \\
\text { (year-month) }\end{array}$ & $\begin{array}{c}\text { Rec end } \\
\text { (year-month) }\end{array}$ & Note \\
\hline 11388000 & $\begin{array}{l}\text { Stony Creek below Black } \\
\text { Butte Dam (Black Butte } \\
\text { Dam) }\end{array}$ & $1955-07$ & 1964-10 & 1990-09 & $\begin{array}{c}\text { Dam completed } 1963 \text { (CDOF, } \\
\text { 2008). }\end{array}$ \\
\hline 11424000 & $\begin{array}{l}\text { Bear River near } \\
\text { Wheatland (Camp Far } \\
\text { West Dam) }\end{array}$ & $1928-10$ & 1964-10 & 2013-12 & $\begin{array}{c}\text { Dam completed } 1963 \text { (CDOF, } \\
\text { 2008). }\end{array}$ \\
\hline 11423800 & $\begin{array}{l}\text { Bear River below Camp } \\
\text { Far West Reservoir } \\
\text { (Camp Far West } \\
\text { Diversion) }\end{array}$ & 1989-10 & 1989-10 & 2013-09 & \\
\hline 11451000 & $\begin{array}{l}\text { Cache Creek near Lower } \\
\text { Lake (Cache Creek } \\
\text { Dam) }\end{array}$ & 1944-10 & $1950-01$ & 2013-12 & $\begin{array}{c}\text { Dam completed } 1910 \text { (CDOF, } \\
\text { 2008). }\end{array}$ \\
\hline 11376150 & $\begin{array}{l}\text { North Fork Battle Creek } \\
\text { below diversion to } \\
\text { Eagle Canyon Canal } \\
\text { (Eagle Canyon Canal } \\
\text { Diversion) }\end{array}$ & $1983-10$ & 1995-10 & 2013-12 & Flow behavior change in 1995. \\
\hline 11418000 & $\begin{array}{l}\text { Yuba River below } \\
\text { Englebright Dam } \\
\text { (Englebright Dam) }\end{array}$ & $1941-10$ & 1970-10 & 2013-12 & $\begin{array}{l}\text { Yuba River Development } \\
\text { Project started } 1970 \text { (YCWA, } \\
\text { 2012). }\end{array}$ \\
\hline 11447650 & $\begin{array}{l}\text { Sacramento River at } \\
\text { Freeport }\end{array}$ & 1948-10 & 1970-01 & 2013-12 & $\begin{array}{c}\text { Far-downstream point (multiple } \\
\text { major impairments). }\end{array}$ \\
\hline 11451300 & $\begin{array}{l}\text { North Fork Cache Creek } \\
\text { near Clearlake Oaks }\end{array}$ & 1983-10 & 1983-10 & 2013-12 & $\begin{array}{l}\text { Dam completed } 1976 \text { (CDOF, } \\
\text { 2008). }\end{array}$ \\
\hline
\end{tabular}




\begin{tabular}{|c|c|c|c|c|c|}
\hline $\begin{array}{c}\text { NWIS site } \\
\text { number }\end{array}$ & $\begin{array}{c}\text { Station name } \\
\text { (upstream dam) }\end{array}$ & $\begin{array}{c}\text { Rec start } \\
\text { (year-month) }\end{array}$ & $\begin{array}{c}\text { Cutoff } \\
\text { (year-month) }\end{array}$ & $\begin{array}{c}\text { Rec end } \\
\text { (year-month) }\end{array}$ & Note \\
\hline & (Indian Valley Dam) & & & & \\
\hline 11370500 & $\begin{array}{l}\text { Sacramento River at } \\
\text { Keswick (Keswick } \\
\text { Dam) }\end{array}$ & 1938-10 & 1950-01 & 2013-12 & $\begin{array}{l}\text { Shasta Dam completed } 1945 \\
\text { (CDOF, 2008). }\end{array}$ \\
\hline 11425310 & $\begin{array}{l}\text { Halsey Powerhouse near } \\
\text { Auburn (Lakewood } \\
\text { Dam) }\end{array}$ & 1980-10 & 1980-10 & 2013-09 & \\
\hline 11376025 & $\begin{array}{l}\text { North Fork Battle Creek } \\
\text { below Macumber Dam } \\
\text { (Macumber Dam) }\end{array}$ & 1980-10 & 1989-10 & 2013-12 & $\begin{array}{l}\text { Dam completed } 1907 \\
\text { (Reynolds and Scott, 1980). }\end{array}$ \\
\hline 11375700 & $\begin{array}{l}\text { North Fork Cottonwood } \\
\text { Creek near Igo } \\
\text { (Misselbeck Dam) }\end{array}$ & 1956-10 & 1956-10 & 1980-09 & $\begin{array}{c}\text { Dam completed } 1920 \text { (CDWR, } \\
\text { 1990). }\end{array}$ \\
\hline 11325500 & $\begin{array}{l}\text { Mokelumne River at } \\
\text { Woodbridge }\end{array}$ & 1924-06 & 1964-10 & 2013-12 & $\begin{array}{c}\text { Dam completed } 1963 \text { (CDOF, } \\
\text { 2008). }\end{array}$ \\
\hline 11458000 & Napa River at Napa & 1929-10 & 1950-01 & 2013-12 & \\
\hline 11446500 & $\begin{array}{r}\text { American River at Fair } \\
\text { Oaks (Nimbus Dam) }\end{array}$ & 1904-10 & 1957-10 & 2013-12 & $\begin{array}{l}\text { Folsom Dam completed } 1956 \\
\text { (CDOF, 2008). }\end{array}$ \\
\hline 11376015 & $\begin{array}{l}\text { North Fork Battle Creek } \\
\text { below North Battle } \\
\text { Creek Dam (North } \\
\text { Battle Creek Dam) }\end{array}$ & 1978-10 & 1978-10 & 2013-12 & $\begin{array}{l}\text { Dam completed } 1912 \\
\text { (Reynolds and Scott, 1980). }\end{array}$ \\
\hline 11407000 & $\begin{array}{l}\text { Feather River at Oroville } \\
\text { (Oroville Dam) }\end{array}$ & 1901-10 & 1969-10 & 2013-12 & $\begin{array}{c}\text { Dam completed } 1968 \text { (CDOF, } \\
\text { 2008). }\end{array}$ \\
\hline 11459150 & $\begin{array}{l}\text { Petaluma River at } \\
\text { Copland Pumping } \\
\text { Station }\end{array}$ & 1998-11 & 1998-11 & 2013-12 & \\
\hline 11406920 & $\begin{array}{l}\text { Thermalito Afterbay } \\
\text { Release to Feather } \\
\text { River }\end{array}$ & 1967-11 & 1969-10 & 2013-09 & $\begin{array}{l}\text { Oroville Dam completed } 1968 \\
\text { (CDOF, 2008). }\end{array}$ \\
\hline 11303500 & $\begin{array}{l}\text { San Joaquin River near } \\
\text { Vernalis }\end{array}$ & 1923-10 & $1970-01$ & 2013-12 & $\begin{array}{c}\text { Far-downstream point (multiple } \\
\text { major impairments). }\end{array}$ \\
\hline 11425500 & $\begin{array}{l}\text { Sacramento River at } \\
\text { Verona }\end{array}$ & 1929-10 & 1970-01 & 2013-12 & $\begin{array}{c}\text { Far-downstream point (multiple } \\
\text { major impairments). }\end{array}$ \\
\hline 11420700 & $\begin{array}{l}\text { Dry Creek near Browns } \\
\text { Valley (Virginia Ranch } \\
\text { Dam) }\end{array}$ & 1964-08 & 1964-10 & 1980-10 & $\begin{array}{l}\text { Dam completed 1963 } \\
\text { (AECOM, 2011). }\end{array}$ \\
\hline 11372000 & $\begin{array}{l}\text { Clear Creek near Igo } \\
\text { (Whiskeytown Dam) }\end{array}$ & 1940-10 & 1964-10 & 2013-12 & $\begin{array}{c}\text { Dam completed } 1968 \text { (CDOF, } \\
\text { 2008). }\end{array}$ \\
\hline 11453000 & $\begin{array}{l}\text { Yolo Bypass near } \\
\text { Woodland }\end{array}$ & 1939-10 & 1970-01 & 2013-12 & $\begin{array}{c}\text { Far-downstream point (multiple } \\
\text { major impairments). }\end{array}$ \\
\hline
\end{tabular}




\subsubsection{Effects of Reservoir Storage Levels on Peak Flows}

The results of the methods described in section 5.1 can be refined, particularly with regard to peak flows, by including information on reservoir storage levels, available as observed historical data and as C2-CalSim output for the future scenarios. The effects of California's two largest reservoirs on peak flows are considered here.

The operations of Shasta Lake and Lake Oroville are guided in part by each reservoir's "rule curve," which determines the amount of the reservoir storage capacity to be reserved for flood control, or the "flood control pool" (Willis and others, 2011). The difference between daily storage and the target storage level (commonly referred to as "top of conservation" storage) is referred to here as "storage excess." Releases of water from reservoir storage are governed by the release schedule. For Shasta Lake and Lake Oroville, the official release schedules require releases when storage excess becomes positive (that is, when there is water in the flood control pool).

Peak impaired flows in the lower Sacramento River Basin are associated with reservoir storage encroaching (or nearly encroaching) on the flood control pool. In other words, the highest outflows occur only when storage excess is relatively high (above zero, or negative but close to zero). In our approach, we use the rule curves for two of the major reservoirs in the Sacramento River Basin-Lake Oroville and Shasta Lake - to help us identify periods in the historical record where reservoirs were operating under similar conditions to those projected. For a given flow location, the largest upstream reservoir (Shasta or Oroville) is used to make these determinations.

An empirical storage excess threshold is established for each of these two reservoirs (discussed in section 5.2.2.1). Storage levels are interpolated from monthly values based on observations for the historical period and on C2-CalSim outputs for the future scenarios. On any future day of the simulation, if the storage excess falls below this threshold, blocks from the historical time series may not be selected if the maximum daily historical storage excess reached during that block exceeds the threshold. However, if the storage excess exceeds this threshold in the future period, the opposite restriction is not implemented. This method effectively implements a rule that prevents peak flows from being translated downstream of major reservoirs during drought years when the reservoir storage levels are below the selected thresholds.

\subsubsection{Modeling the Flood Control Reservation}

The target storage needs to be calculated not only for the future scenarios, but also for the historical period because observed data for historical target storages are incomplete. We therefore implemented a model to calculate the target storage in Shasta Lake and in Lake Oroville according to the guidelines provided in each reservoir's flood control operations manual. In both cases, the target storages calculated for the historical period agreed well with available historical data.

\subsection{Shasta Lake}

The Shasta Lake rule curve is described in the reservoir operating manual (U.S. Army Corps of Engineers, 1977). It is based on a "ground wetness index," which is computed as:

$$
x_{t}=0.95 x_{t-1}+q_{t},
$$

where

$x_{t} \quad$ is the ground wetness parameter,

$q_{t} \quad$ is the inflow (in cubic feet per second) for the current day $t$, and

$x_{t-1} \quad$ is $\quad$ the parameter for the previous day $t-1$. 
$x_{t}$ has the same units as inflow (cubic feet per second) and is constrained by the constants $x_{\min }$ and $x_{\max }$ (defined in equation 7) such that $x_{\min } \leq X_{t} \leq X_{\max }$.

For each of the projected climate-change scenarios, the impaired inflows to Shasta Lake needed for this calculation must be estimated from the unimpaired streamflow produced by RVIC. The inflows are estimated by a series of linear regression models, one for each of the 12 calendar months in which the impaired inflow is the dependent variable and the unimpaired routed streamflow is the independent variable. The observed inflow and unimpaired routed streamflow data from the period 1995-2013 are used to train the models. This period was chosen because it had sufficient observed inflow data.

The ground wetness index is initialized to 100,000 cubic feet per second ( $\left.\mathrm{ft}^{3} / \mathrm{s}\right)$ on October 1 of each year, so that $x_{t}(10 / 01)=100,000 \mathrm{ft}^{3} / \mathrm{s}$. For a given $x_{t}$, the target reservoir storage $s\left(x_{t}, t\right)$ can take a value over the range between a time-invariant minimum storage $S_{\min }$ and a maximum storage $S_{\max }$. The absolute minimum target storage during the flood season is $S_{\min }=3,252,100$ acre-feet (acre-ft), and the maximum target storage during the flood season is $S_{\max }=4,552,100$ acre- $\mathrm{ft}$.

Target storage is calculated as a function of date $t$ and ground wetness parameter $x_{t}$ (fig. 6):

$s\left(x_{t}, t\right)= \begin{cases}\left(S_{\min }-S_{\max }\right) \bullet(t-010 \mathrm{ct}) /(30 \mathrm{Nov}-010 \mathrm{ct})+s_{\max } & \text { for } 010 \mathrm{ct} \leq t<30 \mathrm{Nov} \\ s_{\min } & \text { for } \leq t<23 \mathrm{Dec} \\ a \bullet(t-23 \mathrm{Dec}) /(20 \mathrm{Mar}-23 \mathrm{Dec})+s_{\min } & \text { for 23Dec } \leq t<20 \mathrm{Mar} \\ \min \left(S_{\max }, S_{\min }+a+\left(s_{\max }-S_{\min }\right) \bullet(t-20 \mathrm{Mar}) /(15 \mathrm{Jun}-\right. & \text { for } \leq t \\ 20 \mathrm{Mar})) & 20 \mathrm{Mar}\end{cases}$

where

$a=\left(S_{\min }-S_{\max }\right) \cdot\left(X_{t}-X_{\min }\right) /\left(X_{\max }-X_{\min }\right)+\left(S_{\max }-S_{\min }\right)$,

$x_{\min }=110,000 \mathrm{ft}^{3} / \mathrm{s}$,

$x_{\max }=530,000 \mathrm{ft}^{3} / \mathrm{s}$,

and subtraction of dates indicates the number of days elapsed between dates. 


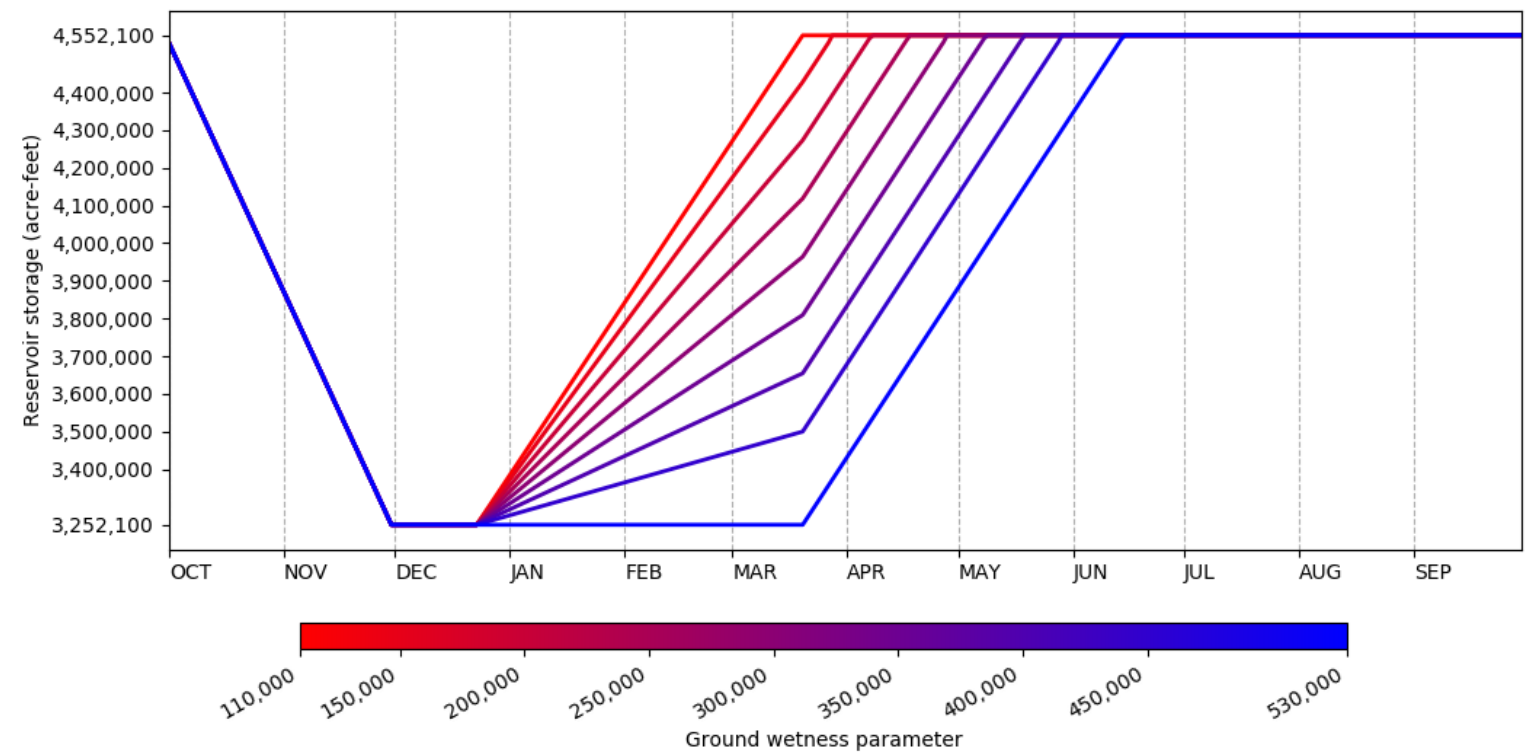

Figure 6. Graph showing rule curve for Shasta Lake, California, calculated over the range of ground wetness parameters.

\subsection{Lake Oroville}

The rule curve for Lake Oroville is described in the reservoir operating manual (U.S. Army Corps of Engineers, 1970). The ground wetness index is computed as follows:

$$
x_{t}=0.97 x_{t-1}+p_{t} \quad \text { under the condition } x_{\min } \leq x_{t} \leq x_{\max },
$$

where

$x_{t}$ is the ground wetness parameter;

$p_{t}$ is the basin mean precipitation for the current day $t$;

$x_{t-1}$ is the ground wetness parameter for the previous day $t-1 . x_{t}$ has the same units as precipitation (units of length);

$x_{\min }=3.5$; and

$x_{\max }=11.0$.

The basin mean precipitation is computed as follows (U.S. Army Corps of Engineers, 1970):

$$
p_{t}=(A B P / N A P) \cdot \sum_{i} p_{t}^{(i)},
$$

where

$A B P=44.1$ inches (in.) (average basin precipitation for the entire Feather River Basin);

$N A P=412.8$ in. (sum of average annual precipitation at eight streamflow stations; table 3); and $p_{t}{ }^{(i)}$ is the precipitation recorded on the current day $t$ at the $i^{\text {th }}$ of the eight stations. 
Table 3. Average annual precipitation measured at eight rain gauges in the vicinity of the Feather River Basin, California, (averaging period unknown) (from M. White, California Department of Water Resources (CDWR), written commun., April 10, 2013).

[CDEC, California Data Exchange Center]

\begin{tabular}{llc}
\hline \multicolumn{1}{c}{ Station name } & CDEC station ID & $\begin{array}{c}\text { Average annual precipitation } \\
\text { (inches) }\end{array}$ \\
\hline Oroville Dam & ORO & 33.4 \\
Strawberry Valley & SBY & 81 \\
Brush Creek (CDWR) & BRS & 72.1 \\
Sierraville (CDWR) & SVL & 26.6 \\
Quincy (CDWR) & QCY & 41 \\
Camptonville (CDWR) & CAM & 55.9 \\
De Sabla (CDWR) & DES & 65.3 \\
Canyon Dam & CNY & 37.5 \\
\hline
\end{tabular}

Because precipitation projections are not available for each of these eight stations (table 3) for the projected climate change scenarios, the basin mean precipitation is calculated directly from the gridded downscaled precipitation data, and for the historical baseline it is calculated from the meteorological dataset by Livneh and others (2015).

The absolute minimum target storage during the flood season is:

$$
\operatorname{S\operatorname {min}}\left(X_{\max }\right)=2,788,000 \text { acre-ft }
$$

and the maximum target storage during the flood season is:

$$
s\left(x_{\min }\right)=3,163,000 \text { acre-ft. }
$$

During the flood season, the value of $\sin \left(x_{t}\right)$ then varies linearly between the two values defined in equations $10-11$ as a function of $x_{t}$ :

$$
\operatorname{Smin}\left(X_{t}\right)=s\left(X_{\min }\right)+a \cdot\left(X_{t}-X_{\min }\right),
$$

where

$a=\left(s_{\min }\left(X_{\max }\right)-s\left(X_{\min }\right)\right) /\left(x_{\max }-x_{\min }\right)=(-50,000$ acre-ft $/$ ground wetness unit $)$.

Target storage is calculated as a function of date $t$ and ground wetness parameter $x_{t}$ (fig. 7):

$s(X t, t)=\left\{\begin{array}{ll}(t-15 \mathrm{Sep}) \cdot\left(S_{\min }\left(X_{t}\right)-S_{\max }\right) /(150 \mathrm{Cct}-15 \mathrm{Sep})+ & \text { for } 15 \mathrm{Sep} \leq t<150 \mathrm{ct} \\ S_{\max } & \text { for } 150 \mathrm{Oct} \leq t<31 \mathrm{Mar} \\ S_{\min }\left(X_{t}\right) & \text { for } 31 \mathrm{Mar} \leq t \\ \min \left(S_{\max }, b \bullet(t-31 \mathrm{Mar})+S_{\min }\left(X_{t}\right)\right) & \end{array}\right.$,

where $b=10,000$ acre-feet per day (acre-ft/d) and $s_{\max }=3,538,000$ acre-ft is the reservoir's capacity. 


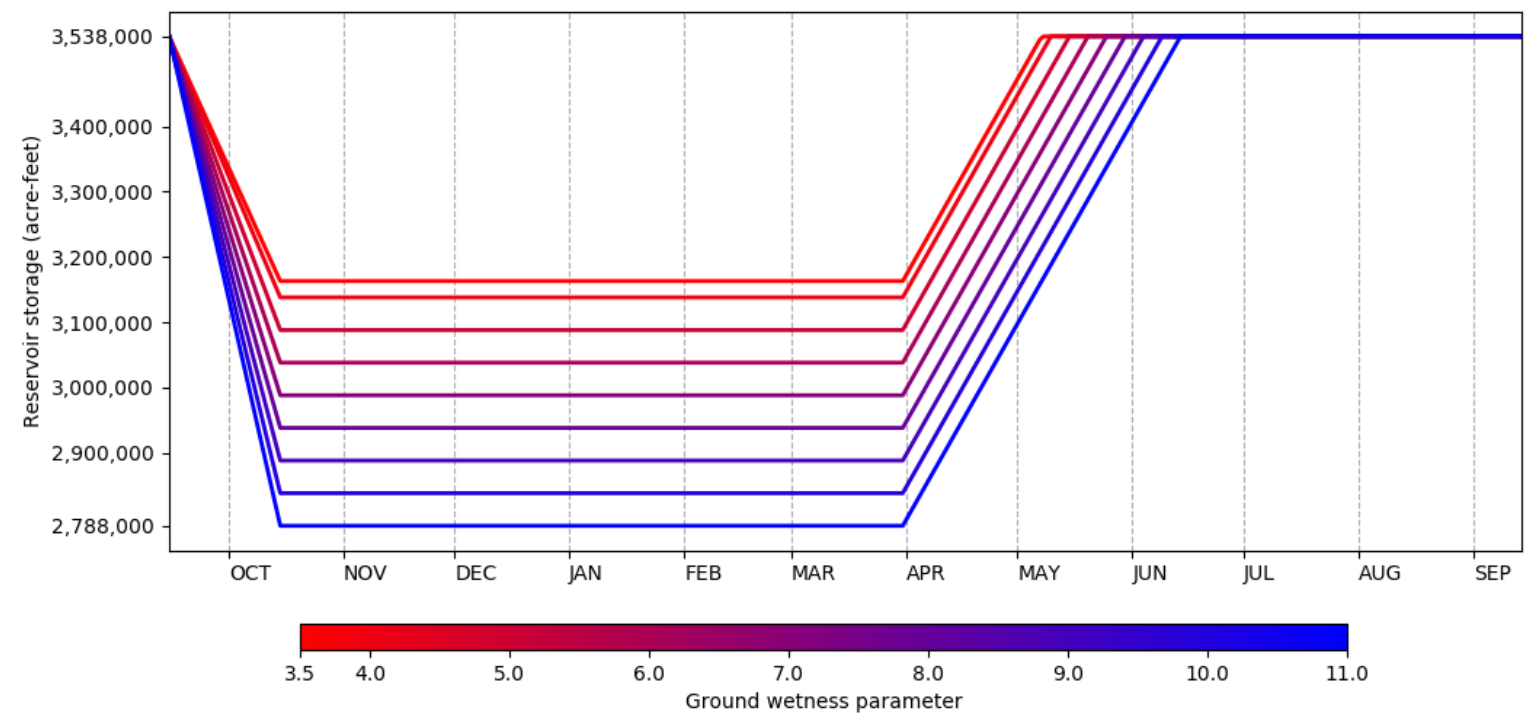

Figure 7. Rule curve for Lake Oroville, California, calculated over the range of ground wetness parameters.

\subsubsection{Storage Excess Thresholds}

As mentioned in section 5.2.2, the target storage levels in Shasta Lake and Lake Oroville are simulated for each day of the projected time series as well as for the period of the historical training data. When searching for matching patterns from the historical training data as described in section 5.1.1, the algorithm checks whether or not the maximum daily storage excess reached during a given block exceeds the storage excess threshold. We used storage excess thresholds of $-500,000$ acre-ft for Shasta Lake and -100,000 acre-ft for Lake Oroville. The relations between these storage excess thresholds and peak impaired flows can be seen in figure 8. When the 30-day running maximum storage excess is plotted against the 30-day running maximum flow, the maximum flow observed within any 30-day window increases when the maximum storage excess is greater than these storage excess thresholds. 

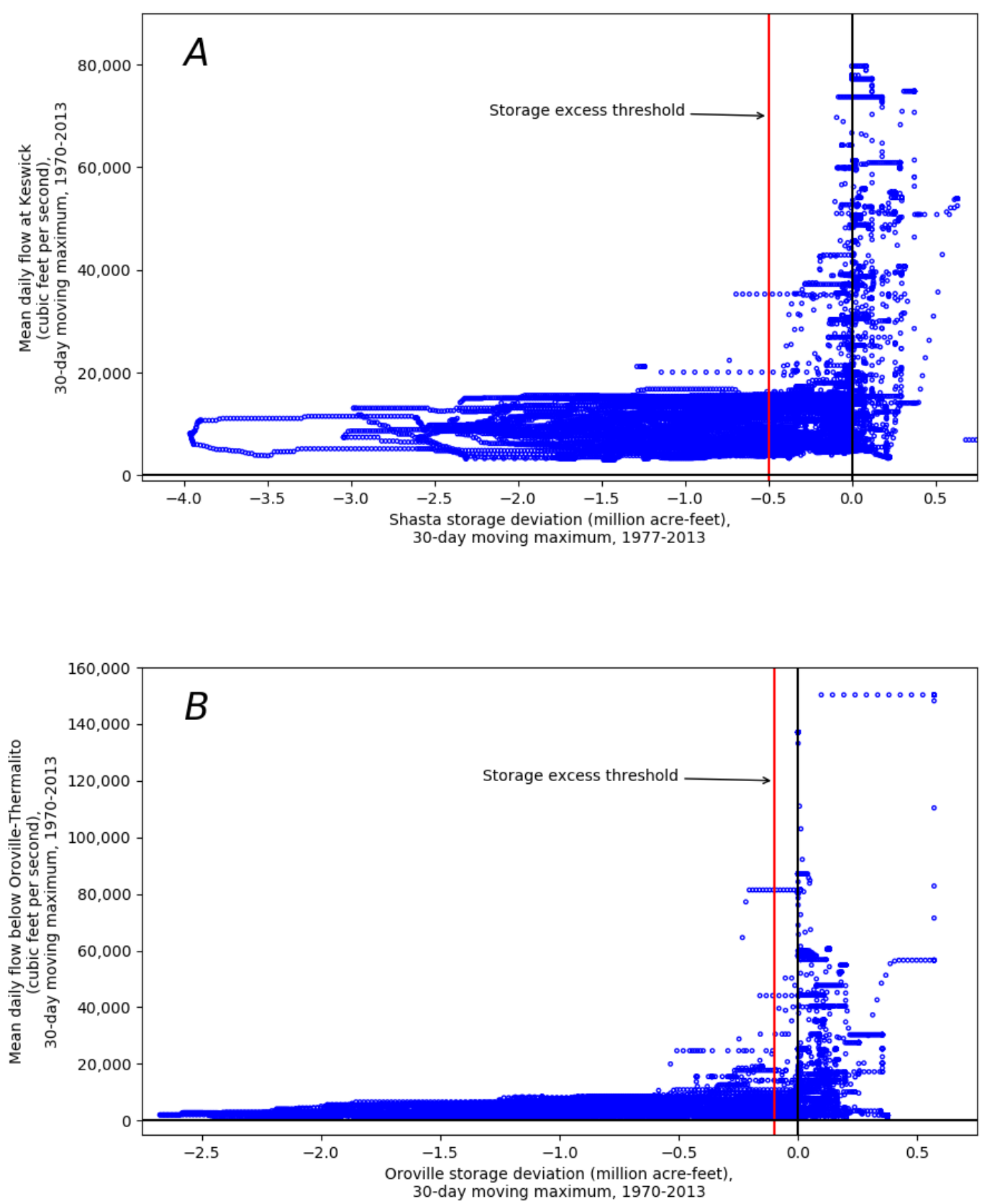

Figure 8. Graphs showing the 30-day moving maximum storage excess in (A) Shasta Lake and (B) Lake Oroville reservoirs, California, versus the 30-day moving maximum daily impaired flow rates. The red lines show the storage excess thresholds (-500,000 acre-feet for Shasta and $-100,000$ acre-feet for Oroville) used to partition the historical training data.

The effect of these storage excess thresholds on selection of patterns from the historical data can be seen in figure 9. When the maximum storage excess $d$ within the block for month $m$ of length $l$ days from the projected time series (using notation introduced in section 5.1.1), or $\max \left(d\left(\boldsymbol{u}_{m}^{f}\right)\right)$, is below the storage excess threshold $D$, a given $l$-day block $n$ from the historical time series may not be selected 
if the maximum daily storage excess reached during that block, $\max \left(d\left(\boldsymbol{u}_{n}^{h}\right)\right)$, exceeds the threshold $D$. The intent of this is to prevent peaks in unimpaired flow from being translated into impaired flow peaks when reservoirs have enough space to capture the high flows.

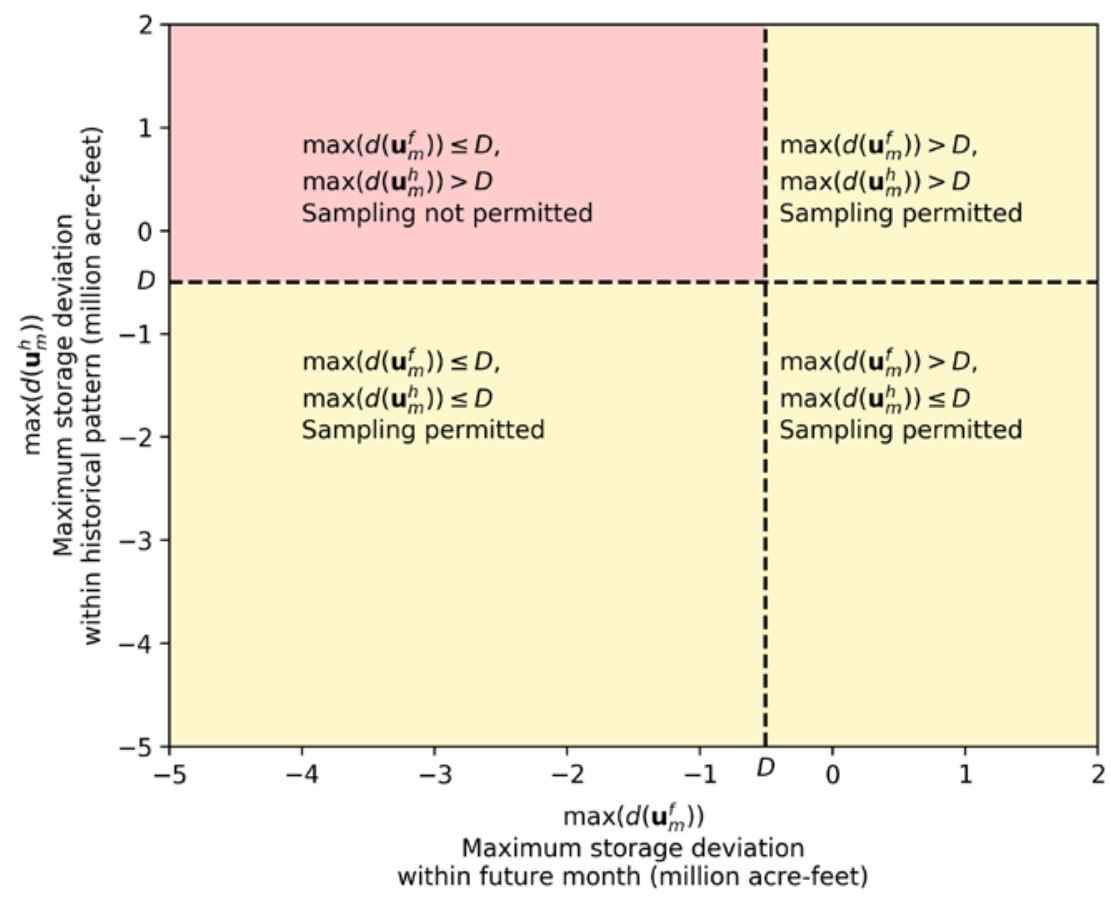

Figure 9. Graph showing implementation of culling for Shasta Lake, California. The same approach is used for Lake Oroville, but with a different threshold). When the maximum storage excess in the projected block is less than the storage excess threshold, the algorithm only samples patterns where the maximum storage excess is also below this threshold $D$.

\subsubsection{Modeling Separation of Flow by Fremont Weir}

Two of the key locations at which the CRESPI method was used to project impaired flows are northern boundary points of the D-Flow FM hydrodynamical model: Sacramento River at Verona and Fremont Weir above Yolo Bypass. Flows that do not overtop Fremont Weir proceed downstream to Verona, so Fremont Weir has the effect of separating Sacramento River flow into two components. We found that the CRESPI method performed better if it was used to project the sum of these two components, with the result being subsequently separated into the two flows using the method described below.

Fremont Weir is the primary source of flow into Yolo Bypass (design capacity 343,000 $\mathrm{ft}^{3} / \mathrm{s}$ ) (Russo, Mitch, comp. and ed., 2010). The remaining sources include the Sacramento Weir, downstream of Verona, and several west-side tributaries including the Knights Landing Ridge Cut, Cache Creek, Putah Creek, and Willow Slough.

Water flows over Fremont Weir into Yolo Bypass when the Sacramento River exceeds a stage of $33.5 \mathrm{ft}$, which corresponds to a flow rate of approximately 62,000 ft $3 / \mathrm{s}$ at Verona (U.S. Army Corps of Engineers, 1999). 
Data for daily discharge over Fremont Weir are not available between July 1976 and January 1984. However, a record of daily flow rates in Yolo Bypass, near Woodland, Calif., is available for the full time series from 1970 through 2010. An analysis of the relation between flow over Fremont Weir and flow over Yolo Bypass for the period 1984-2010 suggests that flows over Fremont Weir during this period can be well approximated by the data from Yolo Bypass at Woodland (fig. 10).

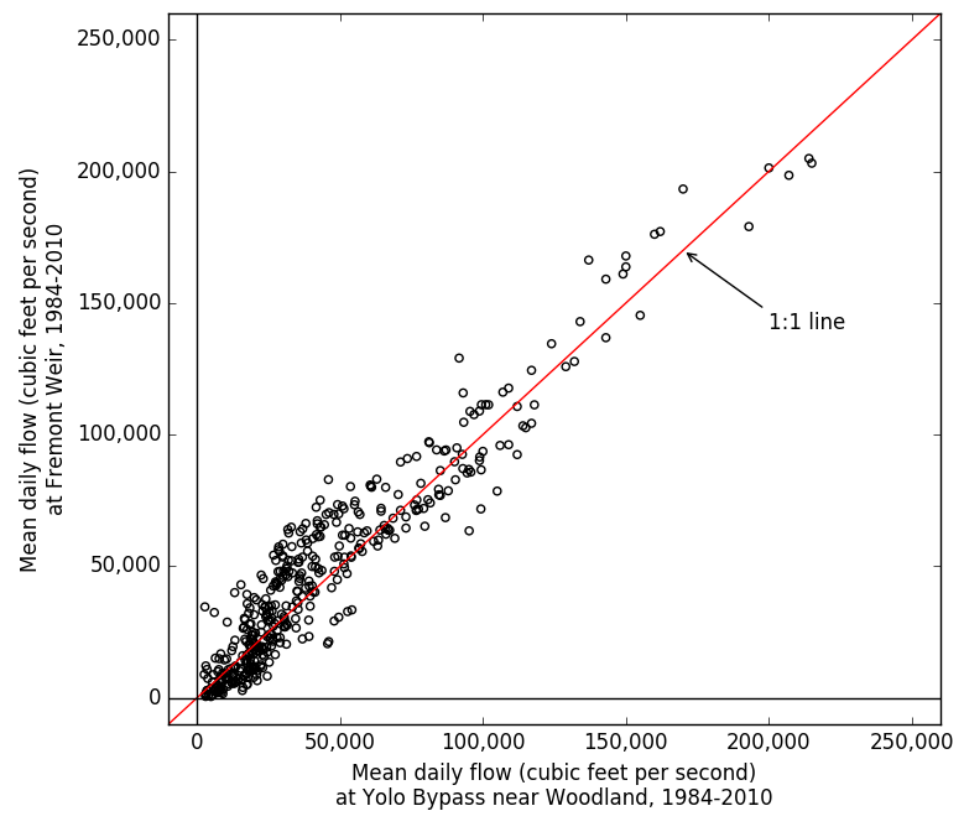

Figure 10. Graph showing mean daily flow over Fremont Weir versus flow in Yolo Bypass near Woodland, California, 1984-2010.

The Woodland data are influenced by the smaller contributions to Yolo Bypass flow from Cache Creek and Knights Landing Ridge Cut. Therefore, using the Woodland gauge as a proxy for Fremont Weir flows implicitly includes these smaller sources in the estimated flows as well. However, the Yolo gauge near Woodland has historically not reported flows under $1,000 \mathrm{ft}^{3} / \mathrm{s}$. To improve the representation of the smaller contributions for Woodland flows under 1,000 ft $3 / \mathrm{s}$, we substitute Cache Creek flows for unreported Yolo flows. Cache Creek is the major source of inflow above the Yolo gauge other than Fremont Weir, for which observed flows have insufficient temporal coverage to be used here. The impact of that omission should be minimal, because overtopping of the Fremont Weir occurs infrequently when flows at Yolo near Woodland are less than 1,000 $\mathrm{ft}^{3} / \mathrm{s}$.

A source of uncertainty is that the Fremont Weir flow signal could attenuate by the time it reaches the Woodland streamflow station. Also, contributions to Yolo Bypass flow from the Sacramento Weir, Putah Creek, and Willow Slough all enter the Bypass below the Woodland gauge and their contributions are not included in flow estimates based on that gauge. Keeping these caveats in mind, we concluded that the relation depicted in figure 10 is sufficiently strong to justify the use of Woodland flows as a proxy for Fremont Weir flows.

With sufficiently complete historical time series for flows at the Sacramento River at Verona and Fremont Weir determined, the next step was to determine how to calculate each component based on their sum, which was calculated in the previous steps of the CRESPI method. We estimate the flow over Fremont Weir by fitting a two-piece linear regression model in which the combined flow is the independent variable and the flow in Yolo Bypass is the dependent variable. Two regressions are estimated from data where combined Verona and Yolo flow are above or below the $62,000 \mathrm{ft}^{3} / \mathrm{s}$ 
threshold. The separate fit for combined flows below the threshold allowed for inclusion of the occasional Fremont Weir flows that occur below the threshold and for contributions from Cache Creek and Knights Landing Ridge Cut. Flows into Yolo Bypass are then estimated by applying the piecewise regression to the projected combined flow at Verona.

\section{Combining C2-CalSim and CRESPI Results}

The projections of daily managed flow produced using the CRESPI method described in section 5 were used directly for smaller basins, as described in section 2.2. For larger basins, it is important to capture the response of management to long-term trends, which could shift managed flow patterns (for example, peak flows) beyond the range of those in the historical data used in CRESPI. In those cases, it was necessary to scale the CRESPI output to more closely represent the response of operations to longterm trends as represented in the C2-CalSim output.

The approach used was inspired by the "epoch adjustment" method used in other studies (for example, Abatzoglou and Brown, 2012). Here, our intent is to retain the representation of daily variability provided by CRESPI while also capturing the more dynamic (not constrained to historical range) response of operations to long-term trends as represented in the C2-CalSim output. For each projection of flows at a given location, a 31-year moving average of monthly averaged flows is calculated for each month of the water year (one time series for all Octobers, another for all Novembers, and so forth) for WYs 1980-2099. This is done for CRESPI and C2-CalSim outputs. All resulting smoothed time series are then divided by their WY 1995 value, corresponding to the WY 1980-2010 average. This normalizes each time series to its own historical average, which can differ from the observed historical average for the GCM scenarios. (Recall that each GCM provides its own realization of the historical period, constrained only by historical greenhouse gas concentrations.) An adjustment factor (AF) time series is then produced by dividing each smoothed, normalized C2-CalSim-derived time series by its CRESPI counterpart. The $12 \mathrm{AF}$ time series for each month of the water year are then collapsed into a single monthly AF time series and interpolated to daily time series using a meanpreserving interpolation (Rymes and Myers, 2001). Finally, each daily CRESPI projection is multiplied by its corresponding daily AF time series, resulting in a projection of managed flows at a given location that possesses realistic daily variability but also preserves long-term trends.

\section{Evaluation of Model Performance}

Flow characteristics for observed and modeled impaired Sacramento River Basin outflow (the sum of flows from the American River at Nimbus, the Sacramento River at Verona, and in Yolo Bypass) for WYs 1980-2013 are shown in figure 11. To evaluate model performance, VIC and RVIC were driven by the observation-based Livneh historical meteorological dataset (Livneh and others, 2015). The resulting RVIC outputs were used to drive C2-CalSim and CRESPI in the usual manner, except that in selecting matching historical patterns, the historical resampling of standard CalSim 2 inputs used in C2-CalSim and the resampling of historical data used in the CRESPI method always excluded the WY or pattern being matched (that is, "leave-one-out"). 


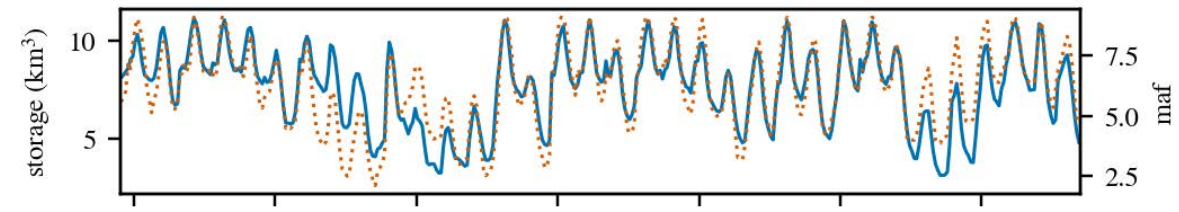

$B$

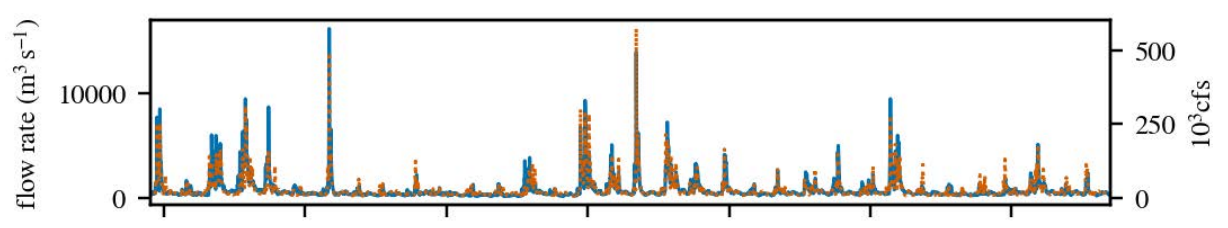

C
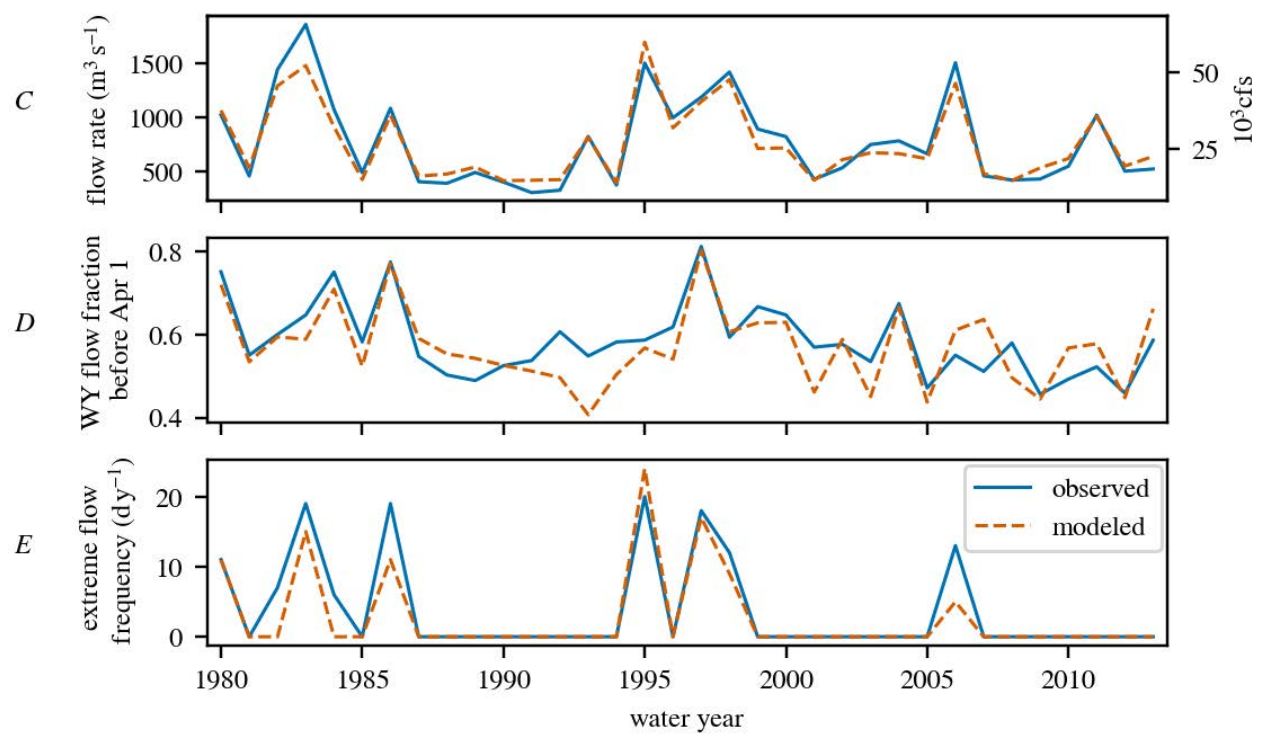

Figure 11. Evaluation of performance of combined C2-CalSim/CRESPI method for Sacramento River Basin, California, outflows for the historical period, water years 1980-2013. Tick marks for top two panels are in the middle of water years (that is, April 1 ). $A$, monthly total major reservoir storage; $B$, daily flow rates; $C$, mean annual flow rates; $D$, fraction of total WY flow arriving before April 1 ; and $E$, frequency of extreme daily flows exceeding the 99th-percentile threshold for the period shown.

Simulated and observed total monthly storage in Shasta, Oroville, and Folsom reservoirs (fig. $11 A$ ) agree reasonably well for our purposes, with a correlation coefficient of 0.87 and an RMS error of 0.83 million acre-feet. Performance for storage in the major reservoirs of the San Joaquin Basin (not shown) is similar, with a correlation of 0.85 and RMS error of 0.57 million acre-feet (the observed total San Joaquin Basin storage averaged over the period shown is 3.7 million acre-feet). The correlation between observed and modeled daily flows (fig. 11B) is 0.88 , and the RMS error is $16,617 \mathrm{ft}^{3} / \mathrm{s}$. A tendency to underestimate peak daily flows is evident. Modeled mean annual flow rate (fig. 11C) is captured well, though the limited number of data points does not support robust error statistics. Finerscale measures such as intra-annual flow timing and peak flow frequency (fig. $11 D$-E) capture the observed variability reasonably well, though a tendency to underestimate peak flows is again evident in the latter.

The main goal of this work is to provide plausible values for managed daily flow inputs to the Bay-Delta estuarine hydrodynamical model, D-Flow FM, under a range of future scenarios. Detailed 
performance metrics for the period WY1980-2013 for sites that serve as inflow boundaries for D-Flow FM are listed in tables 4-5. The locations of these boundaries are shown in figure 1.

Table 4. Intramonthly performance metrics at inflow boundary locations for the San Francisco Bay and Sacramento-San Joaquin Delta (Bay-Delta) estuarine hydrodynamical model, Deltares Flow Flexible Mesh hydrodynamical model (D-Flow FM).

[\%, percent; RSR, ratio of the root mean square error to the standard deviation of observations; r, Pearson's correlation coefficient; See figure 1 for site locations]

\begin{tabular}{|c|c|c|c|c|c|c|}
\hline & Yolo & Verona & Nimbus & Cosumnes & Mokelumne & Vernalis \\
\hline \multicolumn{7}{|c|}{ Simulated versus observed monthly mean flows } \\
\hline$\%$ bias & -6.1 & -2.0 & -0.015 & -6.0 & -1.7 & -1.7 \\
\hline RSR & 0.44 & 0.50 & 0.57 & 0.37 & 0.69 & 0.87 \\
\hline $\mathrm{r}$ & 0.90 & 0.88 & 0.83 & 0.93 & 0.74 & 0.59 \\
\hline \multicolumn{7}{|c|}{ Standard deviation of daily flows within each month } \\
\hline$\%$ bias & -8.5 & -7.6 & -6.7 & -17 & 4.1 & 5.2 \\
\hline RSR & 0.47 & 0.71 & 0.57 & 0.43 & 0.84 & 0.84 \\
\hline $\mathrm{r}$ & 0.88 & 0.73 & 0.83 & 0.90 & 0.60 & 0.61 \\
\hline \multicolumn{7}{|c|}{ Monthly maximum flows } \\
\hline$\%$ bias & -5.1 & -1.9 & -1.8 & -15 & 3.8 & 3.9 \\
\hline RSR & 0.47 & 0.48 & 0.55 & 0.55 & 0.67 & 0.83 \\
\hline $\mathrm{r}$ & 0.88 & 0.89 & 0.84 & 0.84 & 0.75 & 0.63 \\
\hline
\end{tabular}

Table 5. Intra-WY performance metrics at inflow boundary locations for the San Francisco Bay and SacramentoSan Joaquin Delta (Bay-Delta) estuarine hydrodynamical model, Deltares Flow Flexible Mesh hydrodynamical model (D-Flow FM).

[\%, percent; RSR, ratio of the root mean square error to the standard deviation of observations; $r$, Pearson's correlation coefficient; See figure 1 for site locations]

\begin{tabular}{|c|c|c|c|c|c|c|}
\hline & Yolo & Verona & Nimbus & Cosumnes & Mokelumne & Vernalis \\
\hline & \multicolumn{6}{|c|}{ Simulated versus observed monthly mean flows } \\
\hline$\%$ bias & -5.5 & -2.3 & -0.033 & -6.1 & -0.23 & -1.0 \\
\hline RSR & 0.32 & 0.30 & 0.40 & 0.35 & 0.51 & 0.66 \\
\hline \multirow[t]{2}{*}{$r$} & 0.95 & 0.96 & 0.94 & 0.97 & 0.90 & 0.75 \\
\hline & \multicolumn{6}{|c|}{ Standard deviation of daily flows within each month } \\
\hline \% bias & -9.2 & 7.2 & 3.4 & -6.8 & 29 & 24 \\
\hline RSR & 0.24 & 0.40 & 0.39 & 0.37 & 0.56 & 0.72 \\
\hline \multirow[t]{2}{*}{$r$} & 0.97 & 0.93 & 0.92 & 0.93 & 0.87 & 0.74 \\
\hline & \multicolumn{6}{|c|}{ Monthly maximum flows } \\
\hline$\%$ bias & -5.8 & 3.3 & 2.3 & -10 & 25 & 22 \\
\hline RSR & 0.31 & 0.42 & 0.54 & 0.62 & 0.66 & 0.80 \\
\hline$r$ & 0.95 & 0.91 & 0.84 & 0.80 & 0.81 & 0.67 \\
\hline
\end{tabular}

For each flow site, simulated and observed monthly mean flows were calculated. Also, for each month, standard deviation and maximum values for that month's daily flows were calculated. The resulting monthly time series for simulated and observed flows for each site and flow statistic were compared using three performance metrics. These are percent bias, which is 100 times the sum of the monthly differences between simulated and observed flows divided by the sum of the observed monthly flows, the ratio of the root mean square error to the standard deviation of observations (RSR), and the Pearson correlation coefficient $r$. These intramonthly performance statistics are presented in table 4 . The same statistics but calculated at the WY scale instead of the monthly scale, are in table 5. 
Intra-WY and intramonthly statistical performance measures are generally satisfactory for the purposes of future-scenario evaluation, with the best performance at Yolo, Verona, and Nimbus. The magnitudes of biases in mean, standard deviation and maximum are less than 10 percent at these sites, though Yolo's biases are more negative than the others. This reflects the overall tendency of our method to underestimate peak flows, which affects performance in Yolo more strongly than other sites because the Yolo Bypass is fed primarily by peak flows over Fremont Weir. RSR values at Yolo, Verona, and Nimbus are all less than or close to 0.7. Moriasi and others (2007) suggest an RSR of 0.7 as a reasonable threshold for streamflow models. Correlation coefficients are all above 0.7.

At Cosumnes, RSR and $r$ values are good, but bias values are more negative than at other sites, particularly for standard deviation and maximum at the intramonthly scale. Underestimation of Cosumnes flow means, standard deviations and peaks for the period WY1980-2013 may in part be an artifact of the use of training data starting in 1950 in conjunction with positive trends in these flow statistics on the Cosumnes (Booth and others, 2006), possibly associated with rising snowlines resulting from a warming climate. Such trends may have been more effectively mitigated by reservoirs on the other rivers evaluated here than on the largely unimpaired Cosumnes and would not cause similar artifacts at those sites. Fortunately, Cosumnes inflows constitute a small fraction of total Delta inflows.

Mokelumne and Vernalis flows have good bias values at the intramonthly scale (table 4), but intramonthly RSR values are higher and $r$ values are lower than at the other four sites. Intra-WY statistics (table 5) compare similarly, with the exception of high positive biases ( $>20$ percent) in standard deviation and WY-maximum daily flow. A key difference between these two sites and the other four is that in Vernalis' upstream watershed (the San Joaquin River Basin) and, to a lesser degree, in the Mokelumne River Basin, the total storage capacity is comparable or larger than the basin's average total unimpaired WY flow (Knowles, 2000). In cases such as these, where WY flow volumes are comparable or smaller relative to the size of reservoir storage, the CRESPI method as applied here does not perform well by the above measures. This is because the method assumes a strong relation between impaired and unimpaired flows, which is not always the case for these sites. Fortunately, biases at the submonthly and monthly scales (table 4), and at the WY scale (table 5, row 1) are very low for these sites, and the Sacramento River Basin sites which dominate Delta inflow variability and peaks (Yolo, Verona, and Nimbus) perform much better in the metrics for standard deviations and maxima.

Some errors are unavoidable given the nature of this approach and the limitations of the models involved. For example, the version of C2-CalSim used to simulate WYs 1980-2013 contains a static configuration of management infrastructure and strategies representing conditions in 2005, whereas the actual strategies, and to some degree the infrastructure, deviated from this static configuration considerably during WYs 1980-2013. Also, the historical period (WYs 1970-2013) used in the CRESPI method represents a limited range of hydrologic patterns from which to select matches, and even the best matches available may not be good ones, particularly with regard to conditions that occurred relatively rarely, such as extreme flows. Indeed, the "leave-one-out" cross-validation ensures that the maximum flow for the evaluation period is underestimated. This is a likely reason for the tendency to underestimate peaks seen above.

\section{Conclusions}

The joint application of C2-CalSim, a modified version of the California Department of Water Resources CalSim 2 freshwater operations model, and a new algorithm created to estimate daily managed flows (CRESPI) provides a new capability for evaluating the response of the freshwater management infrastructure to scenarios of future change. Although many caveats and opportunities for improvement remain, the basic approach outlined here allows for the direct evaluation of new 
hydroclimatic scenarios, such as those derived from GCM outputs. This approach was developed to provide plausible estimates of managed downstream flows for inputs to watershed sediment and estuarine hydrodynamical and ecological models as part of the CASCaDE2 project but could ultimately prove useful for similar projects whose goal is to translate GCM scenarios into downstream boundary conditions for studies of regional and local climate change impacts. Some of the methods presented here could also be transferable to similar studies in other impaired watersheds.

\section{References Cited}

Abatzoglou, J.T., and Brown, T.J., 2012, A comparison of statistical downscaling methods suited for wildfire applications: International Journal of Climatology, v. 32, no. 5, p. 772-780.

AECOM, 2011, Yuba County 2030 General Plan environmental impact report: Sacramento, Calif., AECOM.

Anderson, J., Chung, F., Anderson, M., Brekke, L., Easton, D., and others, 2008, Progress on incorporating climate change into management of California's water resources: Climatic Change, $\mathrm{v}$. 87, p. S91-S108.

Boé, J., Terray, L., Habets, F., and Martin, E., 2007, Statistical and dynamical downscaling of the Seine basin climate for hydro-meteorological studies: International Journal of Climatology, v. 27, p. 16431655.

Booth E., Mount J., and J. Viers, 2006, Hydrologic Variability of the Cosumnes River Floodplain: San Francisco Estuary and Watershed Science, v. 4, issue 2, article 2.

Brekke, L.D., Maurer, E.P., Anderson, J.D., Dettinger, M.D., Townsley, E.S., Harrison, A., and Pruitt, T., 2009, Assessing reservoir operations risk under climate change: Water Resources Research, v. 45, no. 4.

Brekke, L.D., Miller, N.L., Bashford, K.E., Quinn, N.W.T., and Dracup, J.A., 2004, Climate change impacts uncertainty for water resources in the San Joaquin River Basin, California: Journal of the American Water Resources Association, v. 40, p. 149-164.

California Department of Finance, 2008, Major dams and reservoirs of California, table G-3 of California Statistical Abstract.

California Department of Water Resources, 1990, Final environmental impact report on the revocation of the certificate of approval for Misselbeck Dam and Reservoir: 213 p.

California Department of Water Resources, 2005, CalSim-II model sensitivity analysis study: Technical Memorandum Report, 118 p.

Russo, Mitch, comp. and ed., 2010, Sacramento River Flood Control Project, weirs and flood relief structures: California Department of Water Resources fact sheet, 21 p. California Department of Water Resources, 2014, California Central Valley, unimpaired flow data (4th ed.), accessed February 9, 2015, at http://www.waterboards.ca.gov/waterrights/water_issues/programs/bay_delta/bay_delta_plan/water_q uality_control_planning/docs/sjrf_spprtinfo/dwr_2007a.pdf.

California Department of Water Resources, 2017, California Data Exchange Center, accessed July 17, 2015, at http://cdec.water.ca.gov/.

California Department of Water Resources, Climate Change Technical Advisory Group, 2015, Perspectives and guidance for climate change analysis: California Department of Water Resources Technical Information Record, 142 p.

California Department of Water Resources and U.S. Bureau of Reclamation, 2016, Final Environmental Impact Report/Environmental Impact Statement for the Bay Delta Conservation Plan/California 
WaterFix-Volume I, December, (DOE/EIS-0515.) (ICF 00139.14.): Prepared by ICF International, Sacramento, Calif.

Chung, F.I., and Seneviratne, S.A., 2009, Developing artificial neural networks to represent salinity intrusions in the Delta: World Environmental and Water Resources Congress, p. 1-10.

Dracup, J.A., Vicuna, S., Leonardson, R., Dale, L., and Hanneman, M., 2005, Climate change and water supply reliability: California Energy Commission, Public Interest Energy Research Program, CEC500-2005-053.

Draper, A.J., Munévar, A., Arora, S.K., Reyes, E., Parker, N.L., Chung, F.I., and Peterson, L.E., 2004, CalSim: Generalized model for reservoir system analysis: Journal of Water Resources Planning and Management, v. 130, no. 6, p. 480-489.

Hamman, J., Nijssen, B., Brunke, M., Cassano, J., Craig, A., DuVivier, A., Hughes, M., Lettenmaier, D.P., Maslowski, W., Osinski, R., Roberts, A., and Zeng, X., 2016, Land surface climate in the Regional Arctic System Model: Journal of Climate, v. 29, no. 18, p. 6543-6562.

Healey, M.C., Dettinger, M.D., and Norgaard, R.B., eds., 2008, The state of Bay-Delta science, 2008 : Sacramento, Calif., CALFED Science Program.

Knowles N., 2000. Modeling the Hydroclimate of the San Francisco Bay-Delta Estuary and Watershed. Doctoral dissertation, Scripps Institution of Oceanography, University of California, San Diego.

Knowles, N., Cronkite-Ratcliff, C., Pierce, D.W., and Cayan, D.R., 2018, Data and Associated Code for Projections of Unimpaired Flows, Storage, and Managed Flows for Climate Change Scenarios in the San Francisco Bay-Delta Watershed, California: U.S. Geological Survey data release, https://doi.org/10.5066/P9BMMUEV.

Li, H., Sheffield, J., and Wood, E.F., 2010, Bias correction of monthly precipitation and temperature fields from Intergovernmental Panel on Climate Change AR4 models using equidistant quantile matching: Journal of Geophysical Research, v. 115, no. D10.

Liang, X., Lettenmaier, D.P., Wood, E.F., and Burges, S.J., 1994, A simple hydrologically based model of land surface water and energy fluxes for general circulation models: Journal of Geophysical Research, v. 99, no. D7, p. 14415-14428.

Livneh, B., Rosenberg, E.A., Lin, C., Nijssen, B., Mishra, V., Andreadis, K., Maurer, E.P., and Lettenmaier, D.P., 2013, A long-term hydrologically based dataset of land surface fluxes and states for the conterminous United States: Update and extensions: Journal of Climate, v. 26, p. 9384-9392.

Livneh, B., Bohn, T.J., Pierce, D.W., Muñoz-Arriola, F., Nijssen, B., Vose, R., Cayan, D.R., and Brekke, L., 2015, A spatially comprehensive, meteorological data set for Mexico, the U.S., and southern Canada (NCEI Accession 0129374), version 1.1: National Oceanic and Atmospheric Administration National Centers for Environmental Information, accessed July 7, 2014, at https://doi.org/10.7289/V5X34VF6.

Lohmann, D., Nolte-Holube, R., and Raschke, E., 1996, A large-scale horizontal routing model to be coupled to land surface parametrization schemes: Tellus, v. 48(A), no. 5, p. 708-721.

Martyr-Koller, R.C., Kernkamp, H.W.J., van Dam, A., van der Wegen, M., Lucas, L.V., Knowles, N., Jaffe, B., and Fregoso, T.A., 2017, Application of an unstructured 3D finite volume numerical model to flows and salinity dynamics in the San Francisco Bay-Delta: Estuarine, Coastal and Shelf Science, v. 192, p. 86-107.

Martyr-Koller, R.C., Kernkamp, H., van Dam, A., van der Wegen, M., Lucas, L.V., Knowles, N., Helly, J., Jaffe, B., and Fregoso, T., 2017, Application of an unstructured 3D finite volume numerical model to flows and salinity dynamics in the San Francisco Bay-Delta: Estuarine, Coastal and Shelf Science, v. 192, p. 86-107. 
Maurer, E.P., and Pierce, D.W., 2014, Bias correction can modify climate model simulated precipitation changes without adverse effect on the ensemble mean: Hydrology and Earth System Sciences, v. 18, p. 915-925.

Moriasi, D.N., Arnold, J.G., Van Liew, M.W., Bingner, R.L., Harmel, R.D., and Veith, T.L., 2007, Model evaluation guidelines for systematic quantification of accuracy in watershed simulations: Transactions of the American Society of Agricultural and Biological Engineers, v. 50, no. 3, p. 885900.

Mount, J.F., and Twiss, R., 2005, Subsidence, sea level rise, and seismicity in the Sacramento-San Joaquin Delta: San Francisco Estuary \& Watershed Science, v. 3, no. 1.

National Research Council, 2012, Sustainable water and environmental management in the California Bay-Delta: Washington, D.C., National Academies Press.

Pierce, D.W., Cayan, D.R., Maurer, E.P., Abatzoglou, J.T., and Hegewisch, K.C., 2015, Improved bias correction techniques for hydrological simulations of climate change: Journal of Hydrometeorology, v. 16, p. 2421-2442.

Pierce, D.W., Cayan, D.R., and Thrasher, B.L., 2014, Statistical downscaling using localized constructed analogs (LOCA): Journal of Hydrometeorology, v. 15, p. 2558-2585.

Reynolds, T.S., and Scott, C., 1980, The Battle Creek Hydroelectric System and the Northern California Power Company, 1900-1919, with a 1919-1980 postscript: Historic American Engineering Record CA-2.

Rymes, M.D., and Myers, D.R., 2001, Mean-preserving algorithm for smoothly interpolating averaged data: Solar Energy, v. 71, no. 4, p. 225-231.

State Water Resources Control Board, California Environmental Protection Agency, 1995, Water quality control plan for the San Francisco Bay/Sacramento-San Joaquin Delta estuary: Sacramento, California, 95-1WR.

State Water Resources Control Board, California Environmental Protection Agency, 1999, Water Right Decision 1641: Sacramento, California.

Stern, M.A., Flint, L.E., Minear, J.T., Flint, A.L., and Wright, S.A., 2016, Characterizing changes in streamflow and sediment supply in the Sacramento River Basin, California, using Hydrological Simulation Program-FORTRAN (HSPF): Water, v. 8, no. 10, p. 432.

U.S. Army Corps of Engineers, 1970, Oroville Dam and Reservoir-Report on reservoir regulation for flood control, Appendix IV to Master Manual of Reservoir Regulation, Sacramento River Basin, California.

U.S. Army Corps of Engineers, 1977, Shasta Dam and Lake-Report on reservoir regulation for flood control, Appendix IV to Master Manual of Reservoir Regulation, Sacramento River Basin, California.

U.S. Army Corps of Engineers, 1999, Central Valley flood management systems, Chapter 3 of PostFlood Assessment for 1983, 1986, 1995, and 1997, Central Valley, California.

U.S. Fish and Wildlife Service, 2008, Biological Opinion on the Coordinated Operations of the Central Valley Project and the State Water Project in California, Service file 81420-2008-F-1481-5, accessed November 7, 2016, at https://www.fws.gov/sfbaydelta/Documents/SWP-CVP_OPs_BO_1215_final_OCR.pdf.

U.S. Geological Survey, 2018, National Water Information System database, accessed January 2, 2018, at https://doi.org/10.5066/F7P55KJN.

Vicuna, S., Maurer, E.P., Joyce, B., Dracup, J.A., and Purkey, D., 2007, The sensitivity of California water resources to climate change scenarios: Journal of the American Water Resources Association, $\mathrm{v}$. 43, no. 2, p. 482-498. 
Willis, A.D., Lund, J.R., Townsley, E.S., and Faber, B.A., 2011, Climate change and flood operations in the Sacramento Basin, California: San Francisco Estuary \& Watershed Science, v. 9, no. 2.

Yuba County Water Agency, 2012, Technical Memorandum 2-2-Water Balance/Operations Model: Yuba River Development Project, FERC Project No. 2246. 
ISSN 2331-1258 (online)

https://doi.org/10.3133/off20181101 